This item was submitted to Loughborough's Research Repository by the author.

Items in Figshare are protected by copyright, with all rights reserved, unless otherwise indicated.

\title{
Unlocking electric cooking on Nepali micro-hydropower mini-grids
}

PLEASE CITE THE PUBLISHED VERSION

https://doi.org/10.1016/j.esd.2020.05.005

PUBLISHER

Elsevier BV

VERSION

AM (Accepted Manuscript)

PUBLISHER STATEMENT

This paper was accepted for publication in the journal Energy for Sustainable Development and the definitive published version is available at https://doi.org/10.1016/j.esd.2020.05.005

\section{LICENCE}

CC BY-NC-ND 4.0

\section{REPOSITORY RECORD}

Clements, William, Kimon Silwal, Surendra Pandit, Jon Leary, Biraj Gautam, Sam Williamson, Anh Tran, and Paul Harper. 2020. "Unlocking Electric Cooking on Nepali Micro-hydropower Mini-grids". Loughborough University. https://hdl.handle.net/2134/12578528.v1. 
1

2

3

4

5

6

7

8

9

10

\title{
Unlocking Electric Cooking on Nepali Micro-Hydropower Mini- grids
}

\author{
William Clements, Kimon Silwal, Surendra Pandit, Jon Leary, Biraj Gautam, Sam
}

Williamson, Anh Tran, Paul Harper

\section{Abstract}

Electric cooking has the potential to improve quality of life for people who cook using biomass, both by improving health by eradicating harmful emissions and by removing the need to collect fuelwood, thus freeing up time for other activities. This paper reports on a study that introduced electric cooking as an alternative to biomass-based cooking in 10 households in Simli, a rural Western Nepali community, to assess its feasibility in rural offgrid contexts. Quantitative and qualitative data from a cooking diary study and electrical mini-grid data were collected, assessing the compatibility with micro-hydropower grids and Nepali cooking practices. Datasets of Nepali cooking practices and meal energy requirements were generated, revealing that generally two meals are cooked per day and that, on average, electric cooking consumes $0.25 \mathrm{kWh} /$ day and $0.14 \mathrm{kWh} / \mathrm{meal}$. Participants simplified their cooking practices and found chapati hard to cook on the induction hobs due to inexperience with the cookers. Conversely, dal and rice were found to be easy and fast to cook in pressure cookers on the hobs, leading to a switch from cooking chapati-vegetables based meals to dal-rice based meals. Fuel stacking was common, with participants reverting to their biomass stoves to cook chapati, and due to a lack of reliable electricity supply. Participants found that the transition to electric cooking provided more time for households, due to the reduction in length of time to cook a meal and less time required to collect firewood, and enjoyed cooking on the stoves due to elimination of indoor air pollution. The electrical data analysis showed that control issues, voltage instability, and limited microhydropower plant capacity provide obstacles for electric cooking, especially as it becomes more widely practiced. Nepali people typically cook at the same time as peak demand for electricity, exacerbating the problem of limited capacity in villages like Simli. Only three households continued to use their electric stoves regularly due to a lack of reliable electricity supply, showing that widespread adoption of electric cooking is currently unfeasible. The running costs of electric cooking were lower than the effective labour time costs of fuelwood collection, but initial capital expenses for the electric cooking system and monthly electricity costs are a further barrier to adoption in rural Nepal.

Keywords: Electric cooking, Nepal, micro-hydropower, mini-grid, induction cookers

Abbreviations: 
40 Cooking is an integral part of life for any community. Sustainable Development Goal (SDG) 7 calls for affordable reliable access to modern energy [1]. However, globally, around 3 billion people still use biomass for cooking [2]. The use of traditional cooking stoves has a number of negative impacts, including harmful emissions of black carbon and other particulates, the loss of time spent gathering fuel which could be freed up for income generating activities or improving quality of life, deforestation due to fuelwood collection, and increased greenhouse gas emissions [3]. Indoor air pollution from biomass cooking accounts for the premature deaths of around 4 million people every year, including 22,000 in Nepal [4] [5].

Although improved cookstoves (ICS) and alternative fuels designed to combat these issues have been introduced, uptake has been limited and even amongst adopters, health problems often persist [6] [7]. Significant emission reductions have only been demonstrated by the very best ICS and there is doubt over their health benefits in real-world conditions [6] [7]. Alternative fuels such as liquid petroleum gas (LPG) produce much less carbon dioxide but LPG is still a fossil fuel and requires a robust supply chain, so can at best be seen as a transition fuel in the move to clean, sustainable cooking. Biogas is carbon neutral, but requires appropriate feedstock, and has high initial capital costs [8]. Solar electric cooking has been proposed as a clean, affordable alternative to biomass and other fuels [9] [10] [11]. However, adoption has been limited due to its inconvenience, requiring significant changes in behaviour and strong solar insolation at the time of cooking [10].

\subsection{Electric cooking for developing communities}

60 treated as two separate problems, the time is now right to tackle them together [12]. They identified three key factors that have historically inhibited adoption of electricity for cooking: limited grid access, weak grid infrastructure and perception of price. In weak grids, large load changes cause swings in the grid voltage, something that both national power grids and offgrid systems such as mini-grids can suffer from especially in the Global South. This makes the electrical networks susceptible to low voltage events, knows as brownouts, and complete system failures, blackouts, at peak load times leading to a lack of consumer confidence that power will be available for cooking. On- and off-grid system peak loads often already exceed the limited grid capacity meaning that many utilities and power providers do not encourage electric cooking [13]. Furthermore, even in places where electricity is the cheapest cooking option, it is often perceived as more expensive [14]. A clean cooking program in rural India introduced induction stoves into almost 4000 households, with only $5 \%$ adopting them as their primary cooking method due to fear of higher electricity bills and inadequate power supply [15]. Many rural populations collect their own fuelwood for cooking, so do not see the costs for this directly [16]. However, when costs for fuels are included, either in time or market value, it has been shown that electric cooking is comparable to other fuels for both on- and off-grid consumers [16] [17].

There are several approaches to enable weak grids to support electric cooking loads. Battery-supported electric cooking enables the demand to be distributed throughout the day by charging the battery slowly at off-peak times [18], reducing peak loads and reinforcing grid infrastructure. Power curtailment of electric cookers to reduce peak loads is another potential solution, although this could increase cooking times, as food will take longer to heat up to the required temperature for cooking, and therefore decrease user satisfaction. In 
Bhutan, a demand-side management solution in the form of a device called a GridShare was installed in households in a micro-hydropower (MHP) mini-grid, which regulated usage before severe brownouts occurred and encouraged users to spread their use of large appliances such as rice cookers more evenly throughout the day by communicating the state of the grid to them [19]. This approach was successful in reducing the number and duration of severe brownouts. In Myanmar, a community agreement was reached that if the grid voltage dropped below $180 \mathrm{~V}$, the consumers would not be allowed to switch on their cookers [20].

eCook is a battery-supported electric cooking concept designed to provide poorer households with access to clean cooking and electricity [21] [22]. A cooking appliance is paired with a battery, which can be charged either by solar photovoltaic panels (PV-eCook) or an electrical grid (Grid-eCook) [23]. In 2013, Batchelor proposed that by 2020 the monthly repayments on such a battery-supported cooking system would be comparable to the cost of cooking with charcoal in many developing regions [24], a proposal supported by three UK Government commissioned reports [25-27]. Detailed in-country work by the eCook project has shown that there is strong potential for electric cooking in a wide range of national contexts, including Tanzania, Kenya, Zambia, Uganda, Ethiopia, Myanmar and Bangladesh [21] [23] [28][29]. The eCook project led to the UK Aid Modern Energy Cooking Services (MECS) programme, under which work has shown considerable promise for efficient cooking devices such as electric pressure cookers in East and Southern Africa [22] [29].

\subsection{The Nepali cooking context}

The eCook Global Market Assessment identified Nepal as a promising context for electric cooking [23] [18]. The country has huge renewable energy potential, with $45.6 \mathrm{GW}$ of hydropower technically feasible, and $3 \mathrm{GW}$ and $2 \mathrm{GW}$ of commercially feasible wind and solar power respectively [30]. 87\% of the population now has electricity access [31] but most people $(63 \%)$ live in rural areas with little or no access to modern cooking fuels [32]: $85 \%$ of rural households use biomass for cooking [33].

111 Most electricity in Nepal is generated through hydropower systems [31]. Studies analysing the penetration of electric cooking in Nepal found that successful fuel switching to electricity would increase the use of hydropower resources [34] and the savings would provide capital to support new large-scale hydropower projects [35]. By 2022, the Government of Nepal aims to enable electricity access for the entire Nepali population and initiate an 'electric stove in every household' program, with an increase in electricity generation through the installation of 5,000 MW of hydropower planned [36]. Many off-grid rural communities in

118 Nepal are powered by MHP mini-grids, which are capable of providing electricity to hundreds or thousands of households, but often operate close to full capacity at peak times and are subject to brownouts and blackouts [19].

Although there is significant opportunity in Nepal for electric cooking interventions, little data on Nepali cooking habits exists. In 2002 a study found that rice, lentils and vegetables, were cooked twice a day and meat cooked once a week due to its higher cost [37]. (The authors' personal experience of living and working in Nepal confirms that this is still the case, with meat consumption increasing in more wealthy households.) A 2012 study found that income was low with $28 \%$ of survey respondent households living on less than $\$ 1.2$ per day and that the average quantity of fuelwood used for cooking was $15 \mathrm{~kg}$ per person per week [38]. A 
Western Nepal, found through surveys that the average annual useful cooking energy consumption ranged from 11 to 21.2 kilograms of oil equivalent (128 to $247 \mathrm{kWh}$ ) across different Village Development Committees [39]. The majority of surveyed households used biomass cookstoves. Pokharel et al found fuelwood to be the predominant cooking fuel in districts across the three main climatic regions of Nepal, and that it also provides space heating [40]. However, detailed monitoring of cooking practices and meal energy requirements have never been published.

To examine the feasibility of electric cooking in a rural Nepali context, especially in communities dependent on MHP mini-grids, more detailed research is required into household cooking habits, food energy requirements, acceptance of electric cooking technologies and practices, and mini-grid behaviour under cooking loads. This paper aims to investigate these issues by analysing an electric cooking intervention conducted in Simli, Western Nepal. This case is used to understand how the cooking habits of the community adapted cooking practices through the transition, their views on electric cooking after trialling it, and therefore determine the overall feasibility of such an intervention. The remaining paper is structured as follows: Section 2 introduces the methods used to approach the primary research question; Section 3 details the study site; Section 4 presents the results; and Section 5 analyses the results, developing a deeper understanding of the key elements of a transition to electric cooking in Nepal and highlighting the limitations of the study.

\section{Methodology}

\subsection{Research Context}

150 The overarching objective in this study is understanding the feasibility of electric cooking in off-grid MHP mini-grids in rural Nepal. This is an interdisciplinary problem, with issues able to be broken down into largely socio-cultural, technical and economic factors.

\subsubsection{Socio-cultural factors}

A successful household level transition to clean cooking involves changes in behaviour which can include the cooking of different foods, different quantities of foods, and adapting cooking techniques to suit the new appliance and any new cookware. These may result in real or perceived changes in the size, texture and taste of meals which may influence their desirability. The transition process is fragile due to seasonal changes and no-cost reversal to traditional fuels [41]. These socio-cultural factors lead to two research questions, based around the cook function within a household:

1. What are the current Nepali cooking practices and habits?

2. How compatible is Nepali cuisine with electric cooking?

\subsubsection{Technical factors}

Introducing electric cooking in a mini-grid adds a high-power load to the power system most cooking hotplates draw more than $1 \mathrm{~kW}$. For highly constrained off-grid systems, this additional load will place a severe strain on the supply. Therefore, understanding how the electric cooking load effects the mini-grid will be critical, prompting the following system research question:

3. What are the effects of electric cooking on an MHP mini-grid and how can any adverse effects be mitigated? 
This question also leads to an understanding of the potential for widespread uptake of electric cooking in mini-grids.

\subsubsection{Economic factors}

As previously discussed, households often believe electric cooking to be more expensive than other forms of cooking. To ascertain whether this is just a perception or reality, data on energy consumption, cost and affordability is needed, generating two final questions:

4. What is the daily energy requirement of cooking with electricity and will this vary throughout the year?

5. Are users able to afford the electricity used in electric cooking?

Knowledge of the energy requirements of Nepali cooking is necessary to calculate running costs of electric cooking, and relevant when assessing the technical aspect of feasibility. In order to increase the potential uptake of electric cooking, the spare energy in a mini-grid could be used more intelligently by scheduling household cooking or incorporating energy storage to spread cooking loads throughout the day, requiring data on household cooking energy requirements.

\subsection{Methodologies}

Two methodologies were used to address these research questions: a cooking diary study was conducted on the households ( $\mathrm{HHs}$ ) within the study; and the mini-grid system electrical data was recorded. Overall, the combination of qualitative, quantitative, household and MHP system data enabled analysis of the whole system effect of integrating electric cooking into off-grid supply networks, allowing assessment of its overall feasibility.

\subsubsection{Cooking diaries} The Cooking Diaries Protocols [42] [43] were developed to provide insight into exactly how cooking is performed in a specific context: what do people cook; which fuel and appliance do they use; and how much energy/time required to cook their meals. After transitioning to electric cooking, the methodology observes how cooking habits change: how people adapt; and how well suited the new appliance is to the context. The methodology was employed during the detailed in-country studies conducted by eCook researchers [21] [23] [44]. ICS are most commonly tested using the Water Boiling Test, Controlled Cooking Test and Kitchen Performance Test [45] [46] [47], focussing on stove efficiency, emissions, performance and acceptability. However, none of these provided detailed insight into how people cook and how they adapt their cooking practices to new fuels or appliances, which enables an understanding into the feasibility of technology.

The cooking diaries methodology was adapted for the Nepali cooking context to enable this study [42] [43], by including local meals and cookware. Researchers visited the HHs to explain the purpose of the research and the cooking diaries. For the two-week baseline phase in July 2018, participants cooked as normal on their wood stoves, weighing the fuelwood they used before and after cooking to provide energy data. For the two-week transition phase in August 2018, they were given electric cookers and encouraged to use them for their cooking as much as possible, this time taking energy readings from electrical submeters. There were no seasonal changes in food availability or consumption between the phases. Enumerators visited the $\mathrm{HHs}$ during mealtimes to record the data in the cooking diaries. Energy saving practices such as the use of lids, and any saving of food for later 
214 meals, were recorded, as they can reduce the energy requirements of meals, which is

215 particularly relevant for limited capacity grids.

216 Quantitative data was recorded for the cooking diaries using hanging balances, weighing

217 scales, measuring cups, water measurement jugs, and plug-in energy meters for measuring

218 fuelwood, food and water quantities, and electrical energy consumption. Households were

219 provided with IMEX single ring induction hobs, locally modified to draw a maximum of $1 \mathrm{~kW}$

220 due to limited spare power on the mini-grid, and induction-compatible cookware suitable for

221 Nepali cooking, as detailed in Table 1. Induction hobs were chosen as the efficient electric cookers most similar to wood stoves in principle, as compared to insulated cookers. During baseline phase, HHs used their own cookware as normal. Figure 1 shows participants with the cooker and cookware and using the hanging balance. Cooking diary data on cooking practices was obtained at dish level resolution, whereas energy data was obtained for entire meals as fuelwood could only be recorded before and after cooking.

Table 1: Household-based equipment supplied and used in study.

\begin{tabular}{|c|c|c|}
\hline Equipment & Function & Notes \\
\hline Electric cooker & IMEX induction hob, single ring & $\begin{array}{l}\text { Modified for max. } 1 \mathrm{~kW} \text { draw } \\
230 \mathrm{~V}, 50 \mathrm{~Hz}\end{array}$ \\
\hline Pressure cooker & Cookware for rice, dal & \multirow{4}{*}{$\begin{array}{l}\text { Induction hob-compatible } \\
\text { cookware provided for } \\
\text { transition phase }\end{array}$} \\
\hline Kadhai & Cooking saucepan & \\
\hline Tapke & Cooking saucepan & \\
\hline Chapati pan & Cooking flat plate & \\
\hline Household submeter & $\begin{array}{l}\text { Measure electric cooking energy } \\
\text { consumption }\end{array}$ & SKN-Bentex (manufacturer) \\
\hline Weight balance & Measure weight of fuelwood & Hanging type \\
\hline Weighing scales & Measure food quantities & \\
\hline Measuring cups, jug & $\begin{array}{l}\text { Measuring food and water/tea } \\
\text { quantities }\end{array}$ & \\
\hline
\end{tabular}




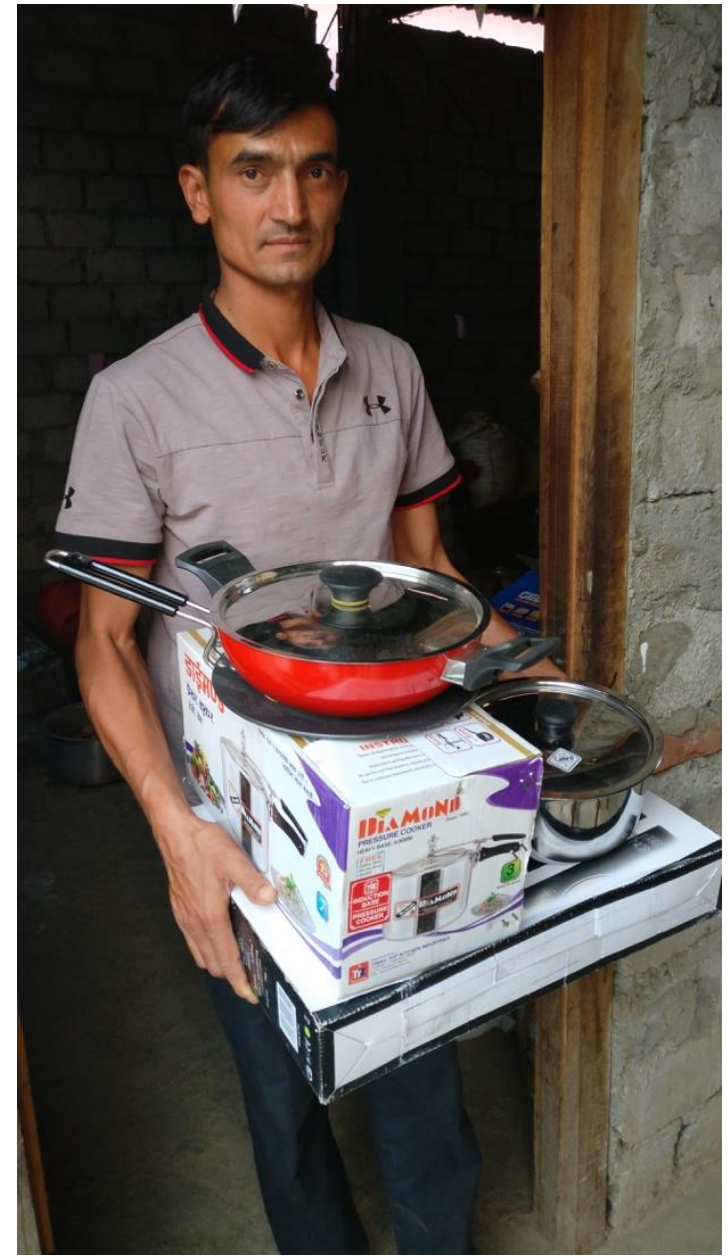

(a)

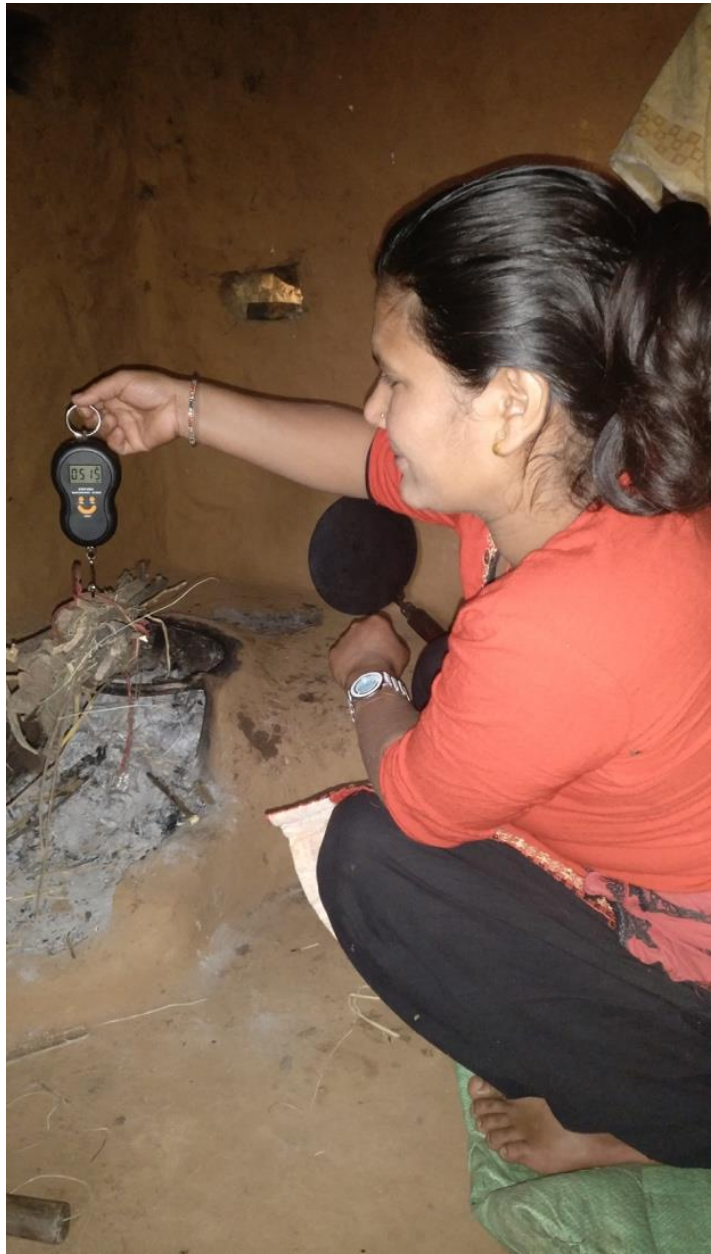

(b)

229 Figure 1: Participants with (a) the provided cooker and cookware and (b) using a hanging balance to obtain the

weight of wood used for cooking.

231 User training was provided by the research team, including: how to cook staple Nepali dishes on the electric cookers; energy saving practices such as the use of lids; and technical information on the cookers, their operation and safety. Furthermore, HHs were encouraged to record their opinions on their cooking experiences and, following the study, exit surveys were conducted as presented in Annex 1: Exit survey. The surveys collected detailed feedback on their experiences and impressions of cooking with the induction hobs in terms of benefits, drawbacks and the ease of cooking different dishes.

\section{$238 \quad 2.2 .2 \quad$ Mini-grid powerhouse electrical data}

239 The mini-grid powerhouse electrical data was recorded to understand how the power

240 constrained MHP system responded to the additional load placed on the system by the 241 household electric cookers.

242 The MHP system has a capacity of $29 \mathrm{~kW}$ and uses a Pelton turbine. In an MHP,

243 pressurised water is converted into mechanical power shaft power by a turbine, which drives

244 an electrical generator. Three-phase power is generated and distributed to HHs in the

245 community, with each phase roughly balanced so the loads are shared equally across all

246 phases. MHP systems typically operate at a constant output power. An Electronic Load 247 Controller (ELC) is used to balance the load on the system through the use of a dump load;

248 as the consumer load decreases, the ELC diverts more power to the dump load, or vice 
versa [48]. The ELC maintains the mini-grid frequency and voltage within desired ranges, in 250 this case around $50 \mathrm{~Hz}, 230 \mathrm{~V}$.

251 Powerhouse electrical data was collected to provide insight into the operation of the mini-grid in Simli village. A CR1000 data logger [49] was installed in the powerhouse with voltage and current sensors, and recorded data at two-second intervals. Figure 2 shows the technical setup of the powerhouse: turbine, generator, ELC, ballast (dump) loads, data logger and sensors. Current and voltage signals for each phase were used by the data logger to calculate frequency, power factor, real power and generation current. Tests were conducted on the induction hobs in the MHP powerhouse in preparation for installation in the HHs, as shown in Figure 3 to verify the system operation.

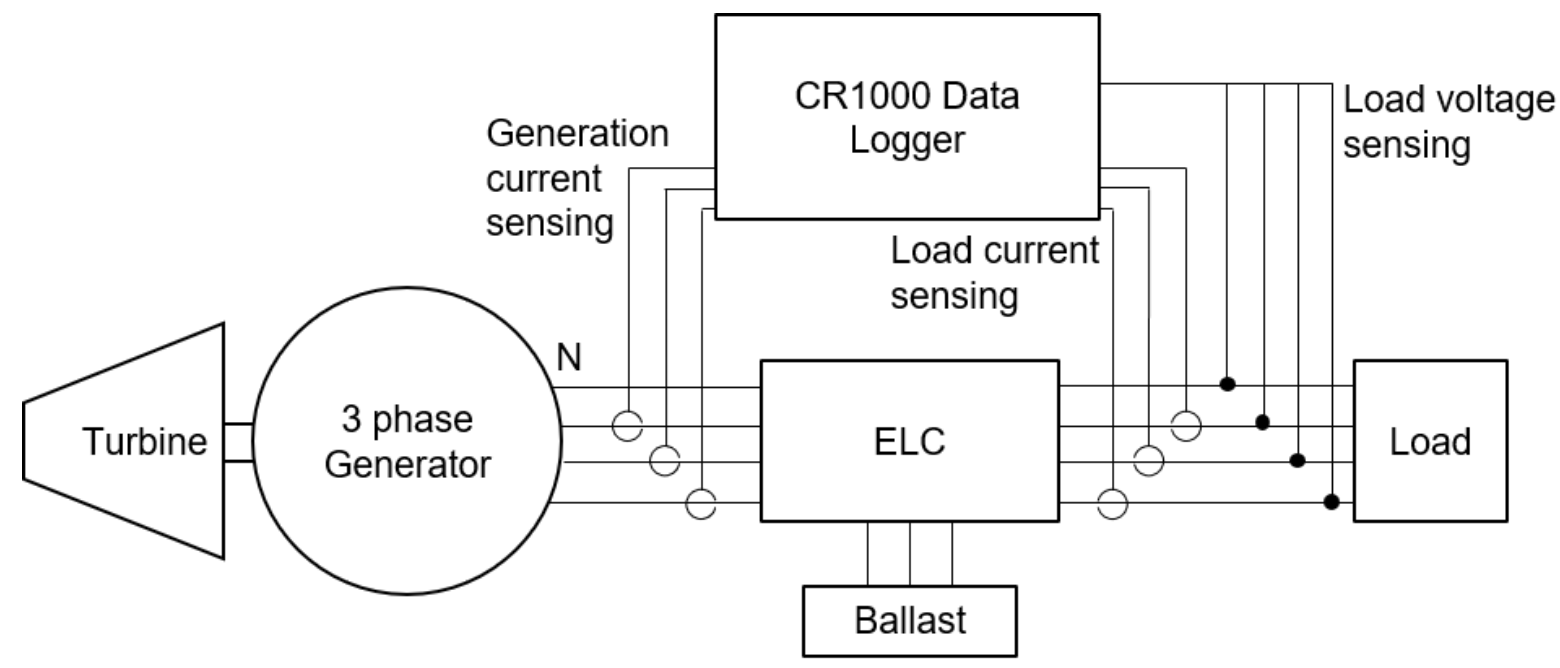

Figure 2: Technical setup of MHP powerhouse, including the turbine, generator, ELC, data logger with current 


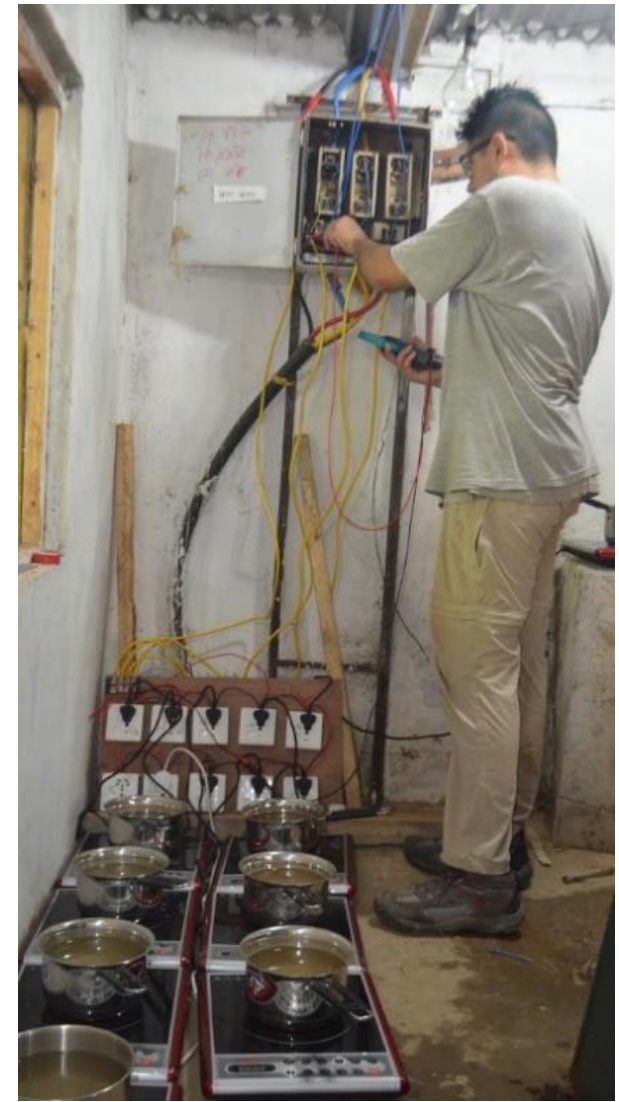

(a)

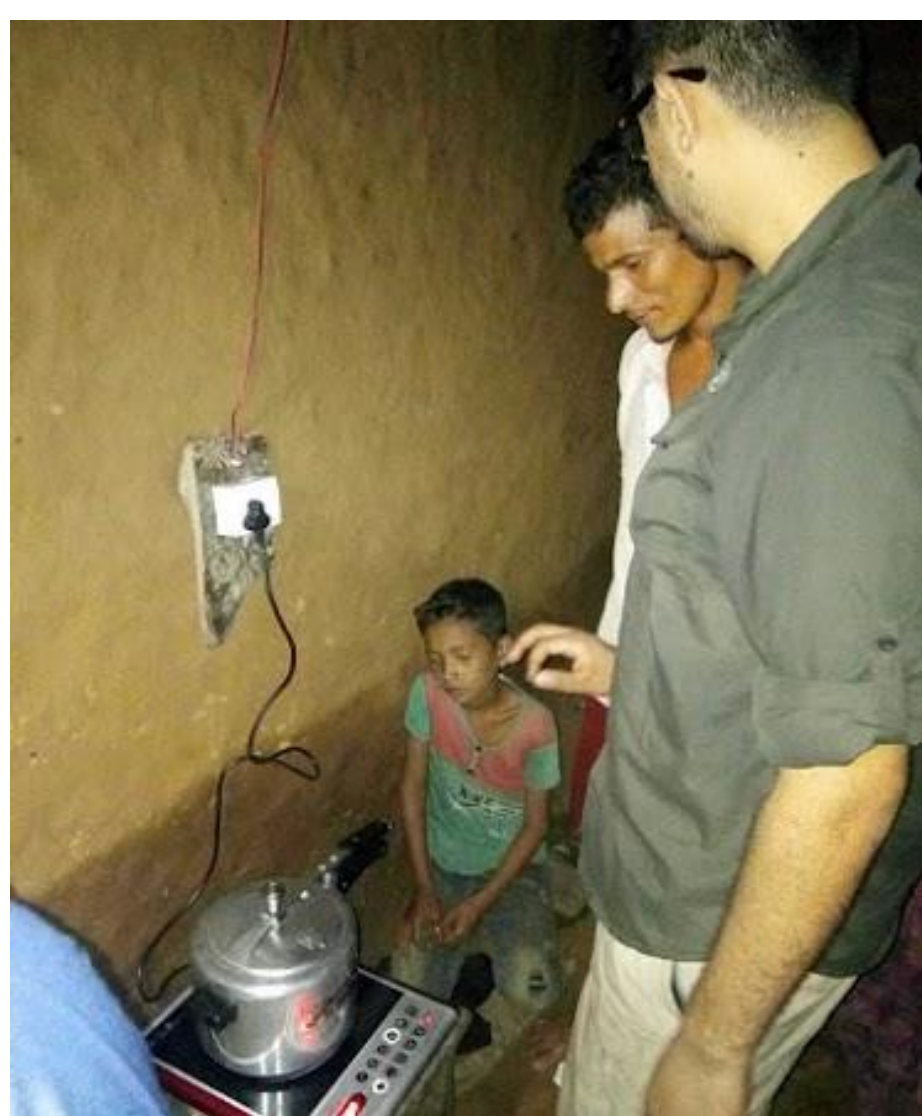

(b)

Figure 3: (a) Testing induction hobs in the MHP powerhouse and (b) user training on cooking with the pressure cookers on the induction hobs.

\section{$264 \quad 2.2 .3$ Data processing and analysis}

265 Cooking diary data was digitised, compiled, cleaned and analysed in Excel using macros 266 and pivot tables. The exit survey results were collected and summarised manually by the research team. Mini-grid electrical data was compiled in Excel and subsequently processed

268 and analysed using Python. Figure 4 presents a flow chart of the work conducted. 


\section{Cooking diary study}

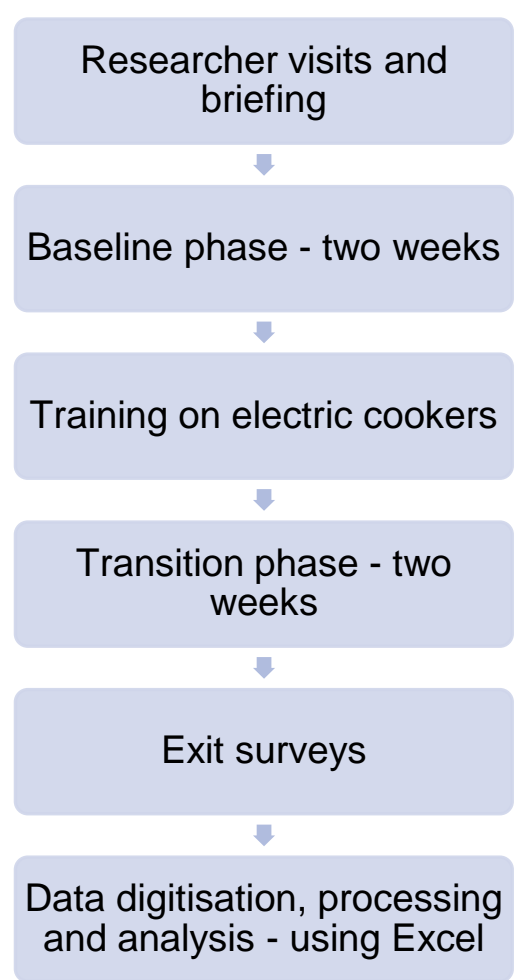

\section{Mini-grid data study}

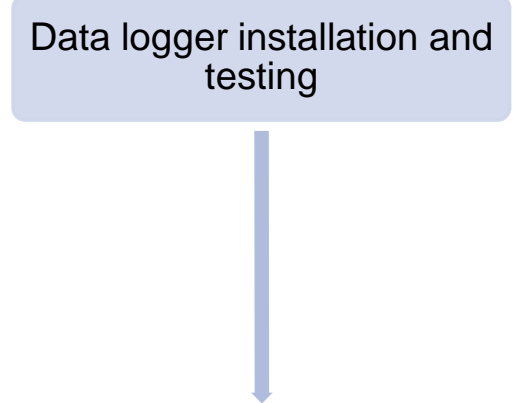

Powerhouse electrical data collection - nine days

Data processing and analysis - using Python

\section{Site details}

272 Simli Village Development Committee (VDC), Rukum district, Western Nepal, was chosen as site for implementation, shown inError! Reference source not found. Figure 5. According to the most recent national census, there are 1044 households $(\mathrm{HHs})$ within the VDC, with an average of 5.1 people per $\mathrm{HH}$, and all but $10 \mathrm{HHs}$ use fuelwood to cook with [50]. Within the VDC, there is a $29 \mathrm{~kW}$ MHP system that provides electricity to around $450 \mathrm{HHs}$, which is operated and managed by a committee of local people. Ten participating $\mathrm{HHs}$ were selected for the study from lists provided by the community representative and MHP owners according to the following criteria:

$\xi \quad H H s$ selected came from a diverse range of ethnic groups;

$\xi \mathrm{HHs}$ were located close to the homes of the enumerators.

The aim of these selection criteria was to ensure that they were representative of rural communities in similar areas of rural Nepal, allowed integration with the mini-grid with minimal reconfiguration, and enabled enumerators to cover a number of $\mathrm{HHs}$ easily during the cooking period. The number of households able to be included in this study was limited by the excess power in the mini-grid. LPG is available in the commercial centre of Simli, with the main demand from hotels and restaurants, but it is not used as much outside of this locality. Where HHs do have LPG, it is normally only used for small, light meals due to the high expense and unreliable supply chain. Of the HHs selected for the study, only one used 291 LPG intermittently. 

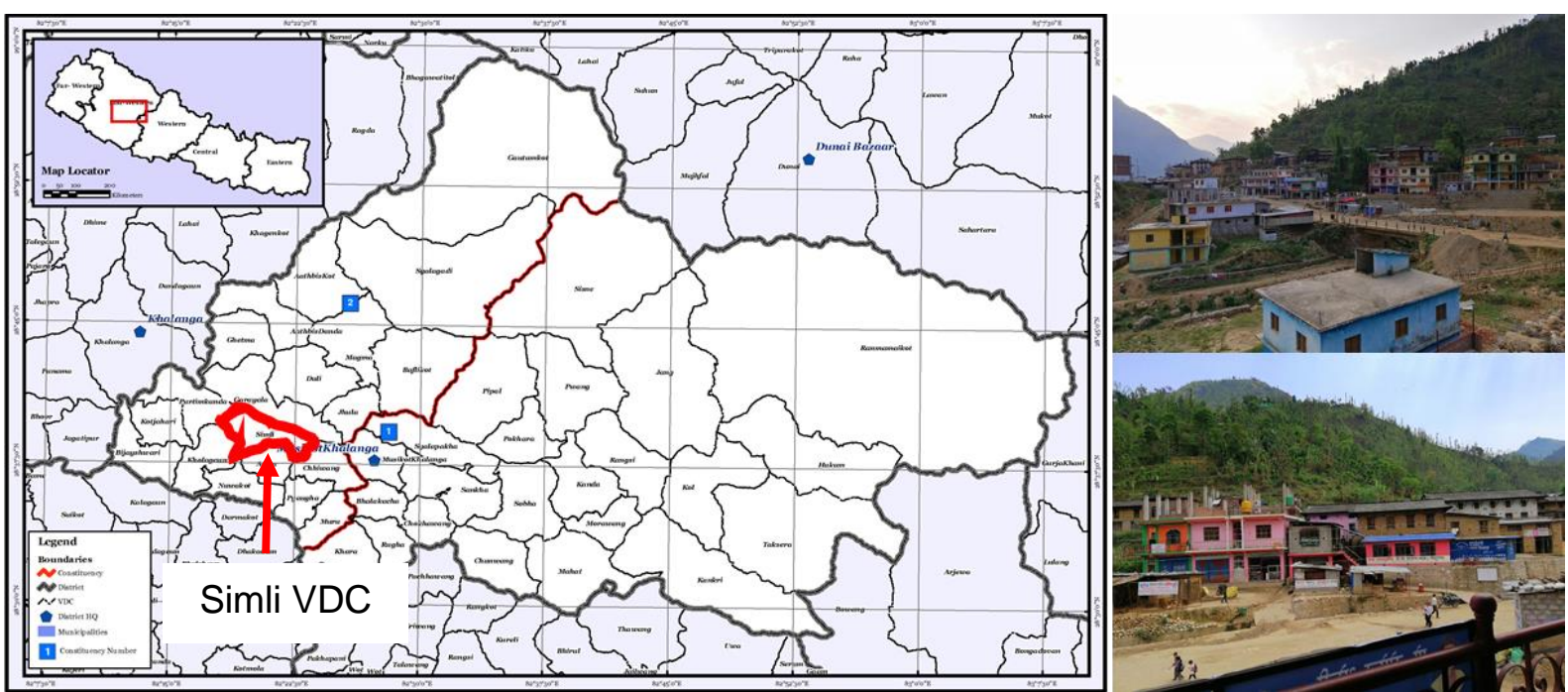

Figure 5: Map of intervention site in Rukum district in Western Nepal, with Simli VDC highlighted (Map [51]), with

\section{Results}

Results are presented according to the research questions. Three of the ten $\mathrm{HHs}$ changed between phases as the original three dropped out due to concerns over the perceived cost of electric cooking. During the processing and analysis of the data it was found that $\mathrm{HHs}$ and enumerators omitted recording some data, including water heating and making tea, and recorded some data erroneously. Furthermore, in the transition phase there was a significant level of fuel stacking, with participants using both electric and wood stoves but not recording the wood stove usage, which was confirmed in the exit survey. The cooking diaries were set up in such a way that it was not clear how to record wood stove usage as well as induction hob usage, and insufficient training led to the enumerators only recording data for electric cooking in the transition phase. However, the data has provided a good initial understanding about cooking habits and energy requirements of rural HHs in Nepal.

\section{4.1 What are the current Nepali cooking practices and habits?}

308 The cooking diary data revealed that the two most commonly cooked meals in the village 309 were dal-rice and chapati-vegetables, with dal-rice-vegetables meals also common. Typical vegetables cooked were found to be various forms of green leaves known as saag, local pumpkin known as pharsi, potatoes, cauliflower, beans and cabbage. Generally, two main

312 meals are prepared each day, in the morning and evening. Tea is usually prepared once or twice per day. Other dishes cooked less frequently included meat, fish, mushrooms and eggs.

Average daily cooking profiles were created from the data by summing the number of $\mathrm{HHs}$ cooking in each ten-minute period across each phase and dividing by the number of days to visually represent the spread of cooking throughout the day, as presented in Figure 6.Error!

\section{Reference source not found.}




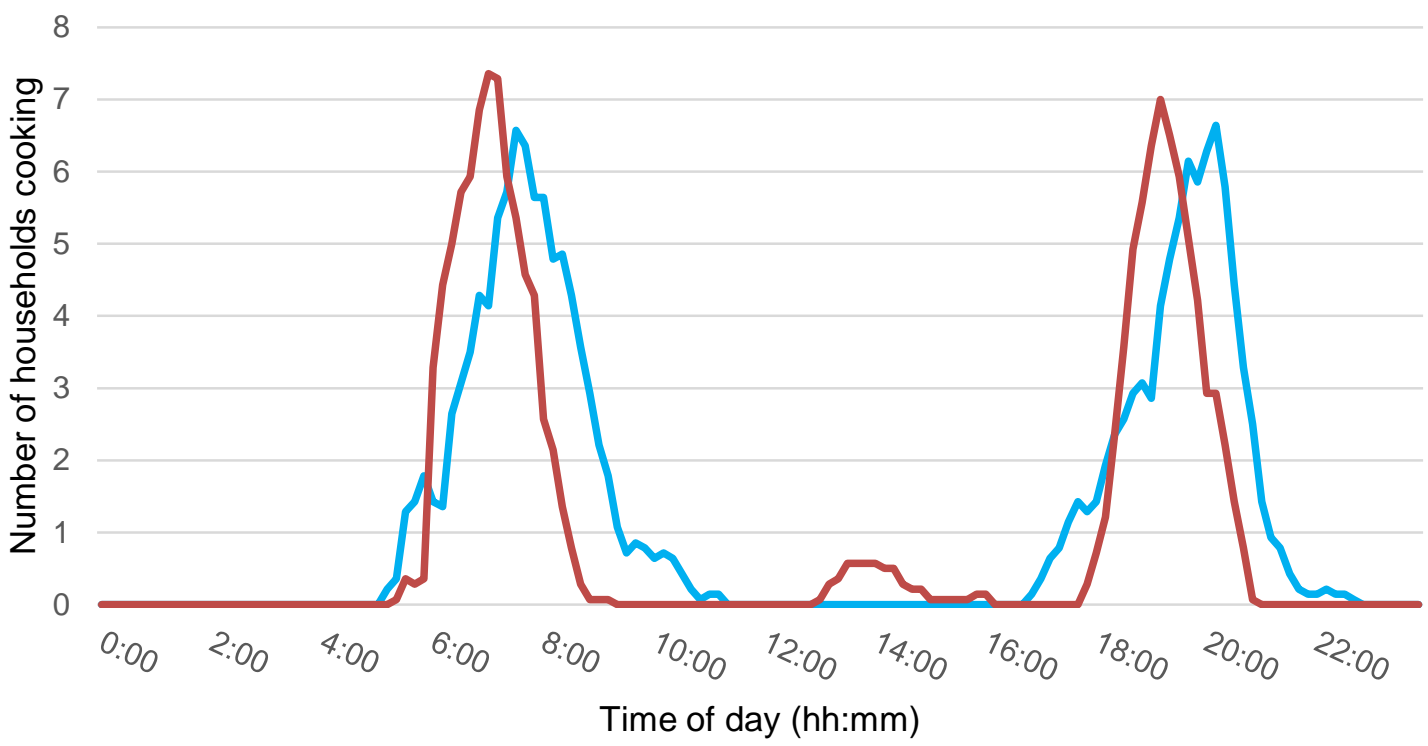

321 The curves provide insight into when Nepali people cook, showing that the peak times for cooking were very similar in each phase at around 7 am and $7 \mathrm{pm}$, with a small shift to cooking earlier in the transition phase. Only eleven cooked lunchtime meals were recorded in the entire transition phase, spread between five different HHs. As with morning tea consumption, it is possible that more lunches were prepared but enumerators and $\mathrm{HH}$ did not record them, however experience in the field showed that lunchtime cooking is rare in Simli.

Table 2 outlines the cookware used for the most cooked dishes in both phases, providing further insight into Nepali cooking practices. Rice and dal are cooked in pressure cookers, the latter consisting of lentils or beans and various spices often including garlic, ginger, turmeric, cumin and chillies. Vegetables are fried in oil and spices.

Table 2: Cookware used in Simli, the phases they were used in, and dishes commonly cooked with each utensil.

\begin{tabular}{|l|l|l|}
\hline Cookware & Phase & $\begin{array}{l}\text { Dishes commonly used to } \\
\text { cook }\end{array}$ \\
\hline $\begin{array}{l}\text { Kadhai - Traditional iron } \\
\text { saucepan with spherical } \\
\text { bottom, and induction version }\end{array}$ & Baseline, Transition & $\begin{array}{l}\text { Rice, Fish, Meat, Vegetables, } \\
\text { Spinach (Saag), Tea }\end{array}$ \\
\hline $\begin{array}{l}\text { Kasaudi - Traditional metal } \\
\text { cooking pot }\end{array}$ & Baseline & $\begin{array}{l}\text { Rice, Mushrooms, } \\
\text { Vegetables, Spinach (Saag) }\end{array}$ \\
\hline $\begin{array}{l}\text { Pressure Cooker, and induction } \\
\text { version }\end{array}$ & Baseline, Transition & $\begin{array}{l}\text { Dal, Rice, Pulses, Curried } \\
\text { Vegetables }\end{array}$ \\
\hline $\begin{array}{l}\text { Deure/Tapke - Traditional iron } \\
\text { pan with flat bottom, and } \\
\text { induction version }\end{array}$ & Baseline, Transition & Water, Milk, Tea \\
\hline $\begin{array}{l}\text { Chapati Pan - thin, flat iron } \\
\text { cooking surface, and induction }\end{array}$ & Baseline, Transition & Chapati \\
\hline
\end{tabular}


version

333

334

335

336

337

338

339

340

341

342

343

344

345

346

347

348

349

350

351

352

Food was always prepared fresh in both phases and never reheated. In the transition phase food was never saved for later, and in the baseline phase there were leftovers from just five meals and only one dish was prepared in advance for the next meal.

\subsection{How compatible is Nepali cooking with electricity?}

The compatibility of Nepali cuisine with electric cooking was investigated by comparing the baseline and transition phases to determine how participants adapted to the electric stoves in terms of what they cooked and how long it took. The comparison also provided further detailed insight into Nepali cooking practices. The three HHs which dropped out after the baseline phase (HHs 8, 9 and 10) were not included in comparisons between phases.

\subsubsection{Menu}

The total numbers of meals cooked from the baseline to the transition phase reduced from 188 to 164 from phase and dishes from 438 to 339 . These reductions can be accounted for by two major reasons: fuel stacking, and by participants simplifying their cooking practices due to inexperience with the electric cookers, cooking fewer dishes per meal. In the baseline phase, chapati-vegetables was the most frequently cooked meal, whilst in the transition phase it was dal-rice, as presented in Figure 7. Participants reported finding dal and rice easy and fast to cook in pressure cookers on the electric cookers and, due to difficulty experienced cooking chapati, therefore increased their consumption of dal-rice meals, reducing their chapati consumption or reverting to wood cooking for chapati.

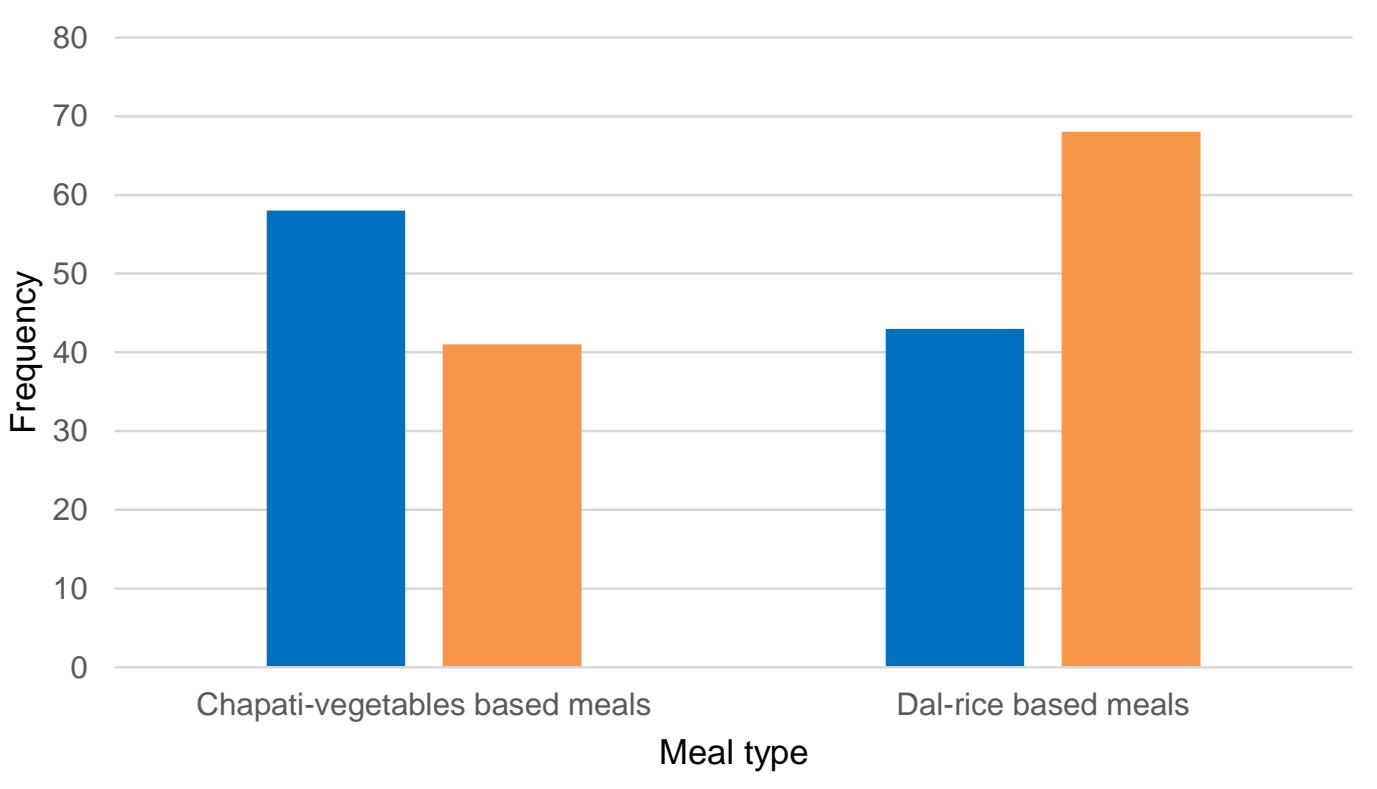

Figure 7: Frequency of most common meals in each phase.

Figure 8 breaks down meals into their constituents, comparing the total numbers of each of the common dishes cooked in each phase. Chapati consumption reduced from 98 to 56 meals. Vegetables were often cooked as part of dal-rice meals and therefore still cooked frequently in the transition phase. Dal consumption increased from 56 to 81 meals, while rice 
consumption was similar in both phases. Rice is typically eaten as part of many meals, including alongside meat, fish and mushrooms in the baseline phase.

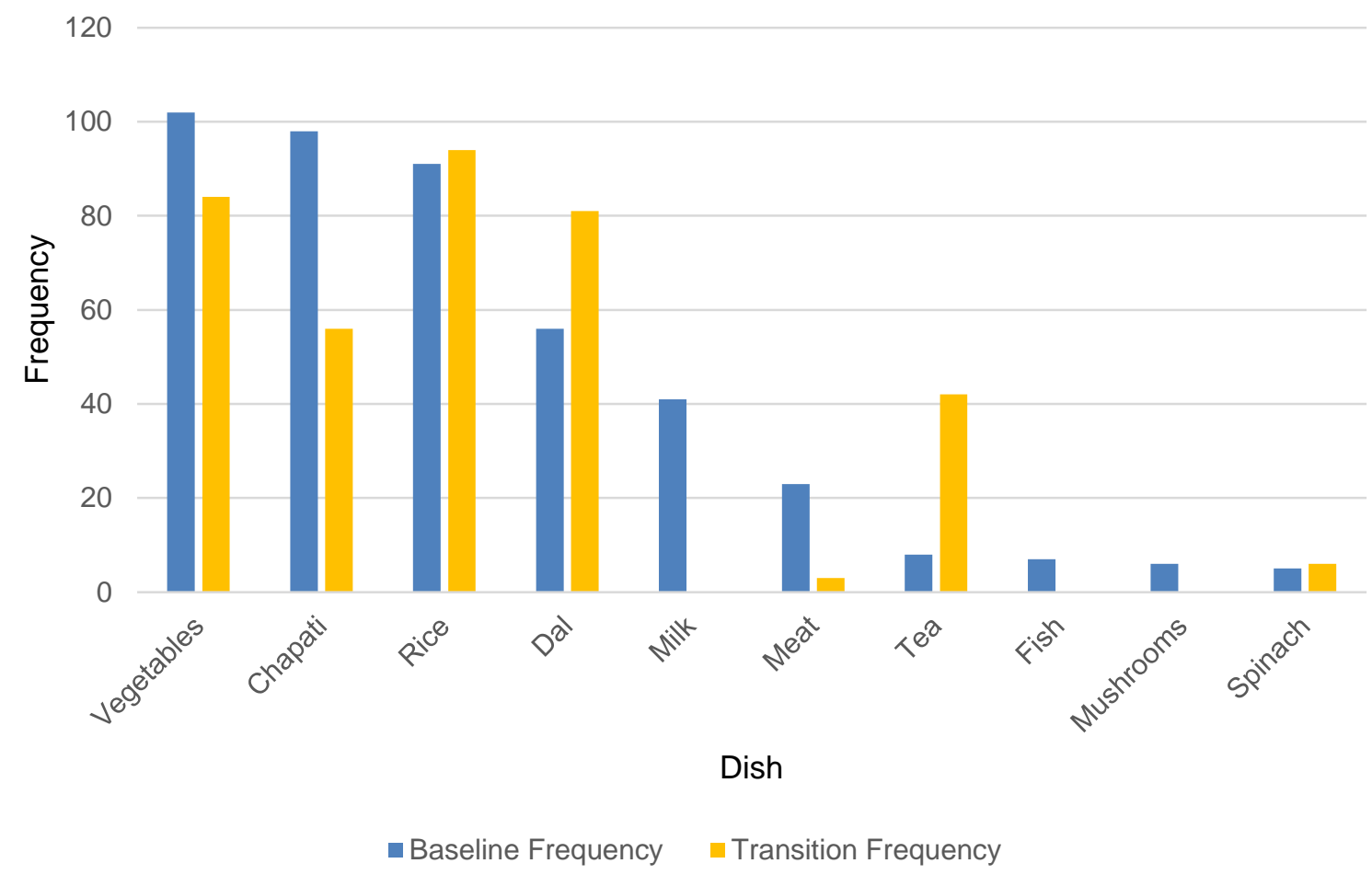

363 Milk, fish and mushroom dishes were not recorded at all in the transition phase, with the 364 former cooked on wood stoves due to large quantities of milk for meals and animals requiring large pans which are incompatible with induction hobs. Although meat was cooked by most $\mathrm{HHs}$ in the baseline phase, often with rice, its consumption reduced significantly from 23 to 3 in the transition phase.

\section{$368 \quad 4.2 .2$ Cooking Durations}

369 Figure 9 presents and compares the overall average cooking times and quantities of 370 ingredients cooked for the common dishes across the phases. 


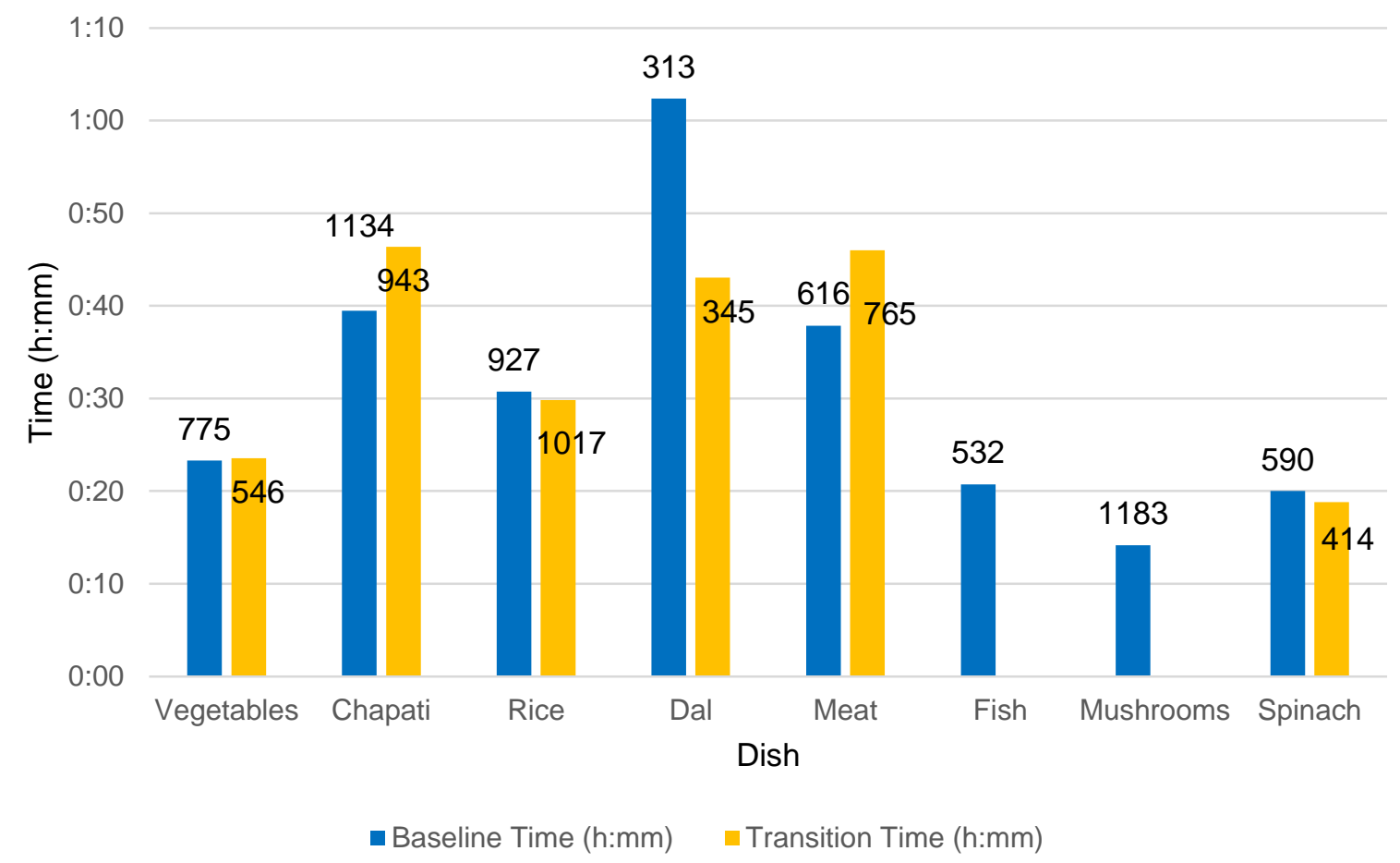

Figure 9: Average cooking times of commonly cooked dishes in each phase labelled with average quantities of ingredients in grams.

375 The cooking time for chapati increased significantly between the two phases, from 39 to 46 376 minutes, but the amount of flour used for the bread reduced, whereas the dal cooking time 377 decreased significantly from 62 to 43 minutes for a similar amount of lentils. Participants 378 reported in exit surveys that dal and rice were both easier to cook with electricity than wood 379 stoves, whereas chapati was more difficult.

\section{4.3 What are the effects of electric cooking on an MHP mini-grid?} Mini-grid powerhouse electrical data was collected for a period of nine days, starting on $16^{\text {th }}$ August. One morning of normal loading data with no electric cooking was recorded on $16^{\text {th }}$ August. Six days of data with electric cooking were recorded from the start of the transition phase on $19^{\text {th }}$ August, after the completion of induction hob tests in the intervening days. The presence of other loads on the system and lack of powerhouse electrical data for normal operation meant that it was not possible to isolate induction cooking load profiles. These loads included $\mathrm{HH}$ lighting, phone charging and televisions. Larger loads from hotels, restaurants, bakeries and metal workshops, and three phase industrial loads for milling and grinding made up the rest of the village electricity demand.

390 Figure 10 shows normal operation of the mini-grid, with the voltage stable at around $230 \mathrm{~V}$ 391 and a load of $10 \mathrm{~kW}$ met comfortably by the MHP. 


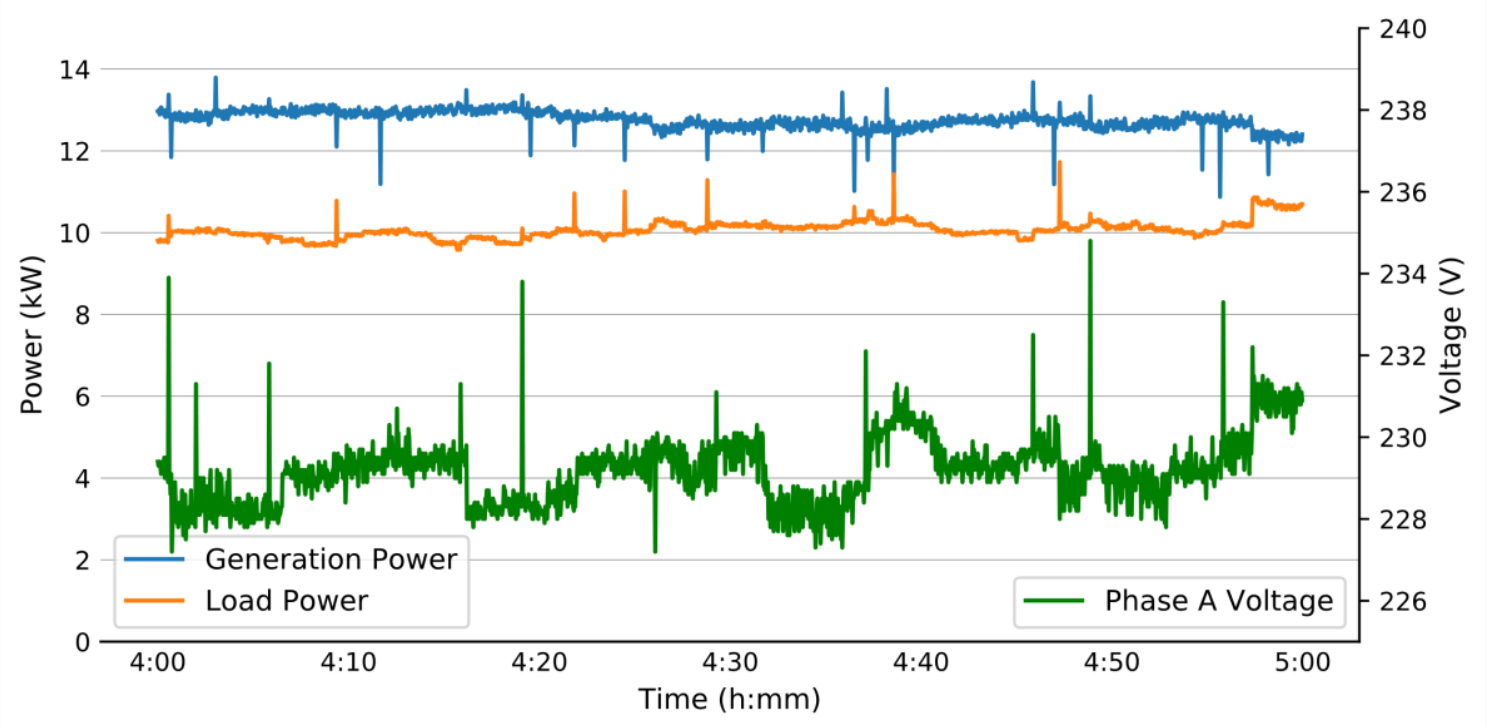

Figure 10: Variation in the total load and generation power across the three electrical phases, as well as one of the phase voltages, in the morning on 16th August 2018.

395 However, there were issues with the control and operation of the MHP mini-grid.

396 Figure 11 shows the total load and generation power across the phases, as well as the voltage of phase 1 , on $23^{\text {rd }}$ August, a few days into the transition phase. The ELC should allow the generation power to be set at a constant level so that the system can absorb load changes without significant variation in voltage and frequency by diverting excess power to dump loads. However, a limitation of the control system meant that the generation power varied constantly, as shown in

Figure 11, with each phase current generally following a pattern similar to the load current. It was not possible to operate the ELC in full load condition as the ballast loads were not rated for this, which meant that an operator was required to respond to changes in load by adjusting the turbine butterfly valve to correct the voltage and frequency. Therefore, the response time was far longer than it would be for a system including a fully functioning ELC, with voltage and frequency deviations more prevalent.

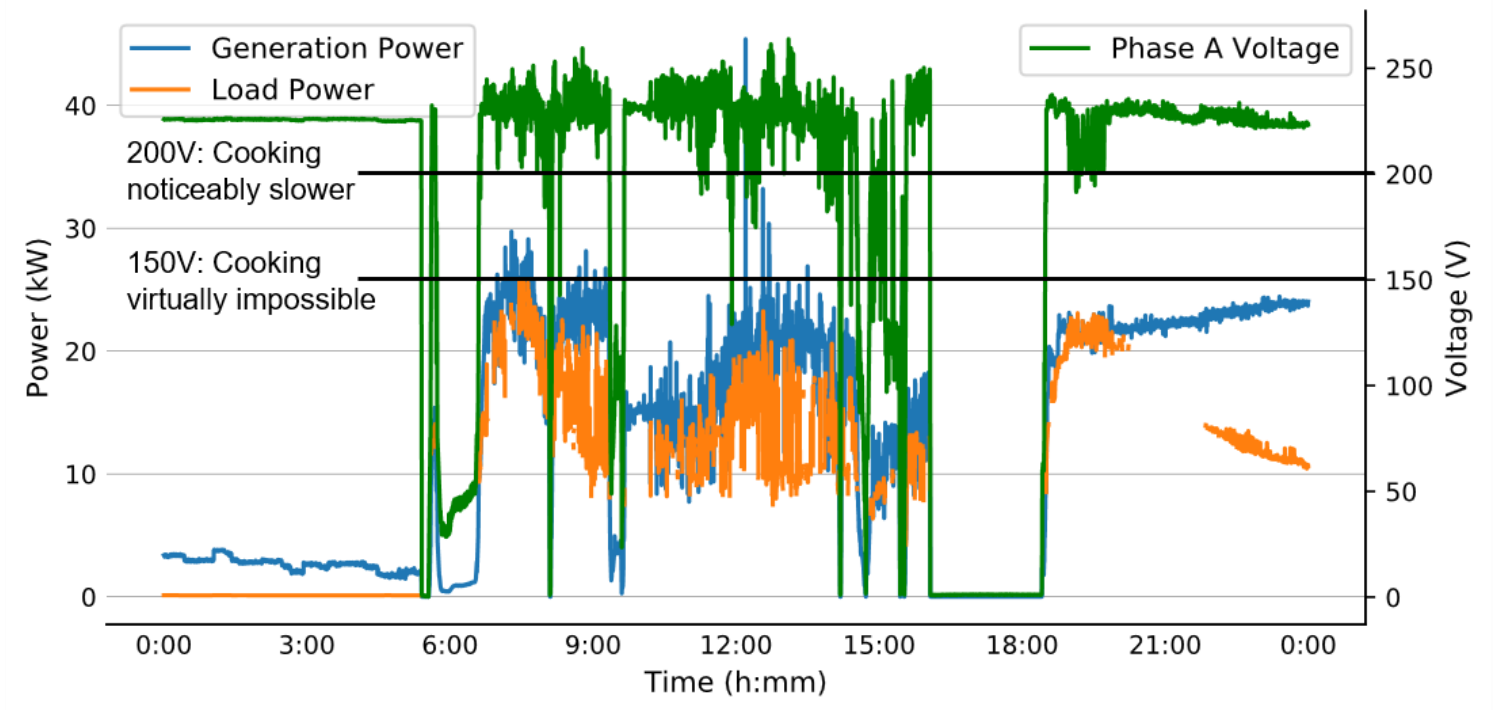


411 Furthermore, as seen in Figure 11 for $23^{\text {rd }}$ August and reported in the exit surveys, there

412 were many blackouts across the transition phase. The operator usually shuts the system

413 down for a short period of time each day, but the data show blackouts were much more

414 frequent. One cause was the wooden distribution poles falling down or requiring

415 maintenance due to poor material condition, with six HHs suffering blackouts on $24^{\text {th }}$ August

416 due to this failure. The participants also described frequent brownouts, which led to

417 uncooked food in periods where the system was running. As shown in

418 Figure 11, the voltage often dropped as low as $50 \mathrm{~V}$ for short periods of time. The authors'

419 experiences have shown that cooking is slower at $200 \mathrm{~V}$ and virtually impossible below 150

$420 \mathrm{~V}$.

\subsection{How much electrical energy is required to cook with electricity?}

422 The cooking diaries provided datasets of Nepali cooking habits and energy requirements, 423 useful for technical understanding of the cooking context and for comparing the costs of 424 cooking fuels. For the baseline phase, energy consumption was calculated by converting the 425 weight of wood used for cooking into kilowatt-hours using a calorific value for wood of 4.42 $426 \mathrm{kWh} / \mathrm{kg}$ [52]. Meal records of milk and tea on their own were excluded from energy per meal analysis as they were not considered meals and would reduce the average energy per meal significantly. However, they were included in daily energy analysis as they contributed to $\mathrm{HH}$ daily energy requirements. As expected, due to the low efficiency of biomass cooking compared to electricity, average daily and meal energy consumption per capita were 20 times higher for the baseline phase $(5.22 \mathrm{kWh} /$ day and $2.61 \mathrm{kWh} /$ meal $)$ than for the transition phase $(0.25 \mathrm{kWh} /$ day and $0.14 \mathrm{kWh} / \mathrm{meal})$.

433 All HHs within the study were cooking for more than one person at each mealtime. With fuelwood, there are significant efficiency savings for HHs cooking for bigger families, whereas with electric cooking the average meal energy per capita is independent of the number of people cooked for, as shown in Figure 12. For wood, the negative relationship shows that the energy required for cooking does not vary much with the number of people cooked for, as for any cooking the stove must be lit and once alight is difficult to turn down or turn off. Therefore, it is subject to significant losses for all cooking, whether heating water or tea for one or cooking dal and rice for ten. However, these losses represent a higher proportion of the total energy used for smaller and quicker heating events, such as making tea or cooking vegetables. 


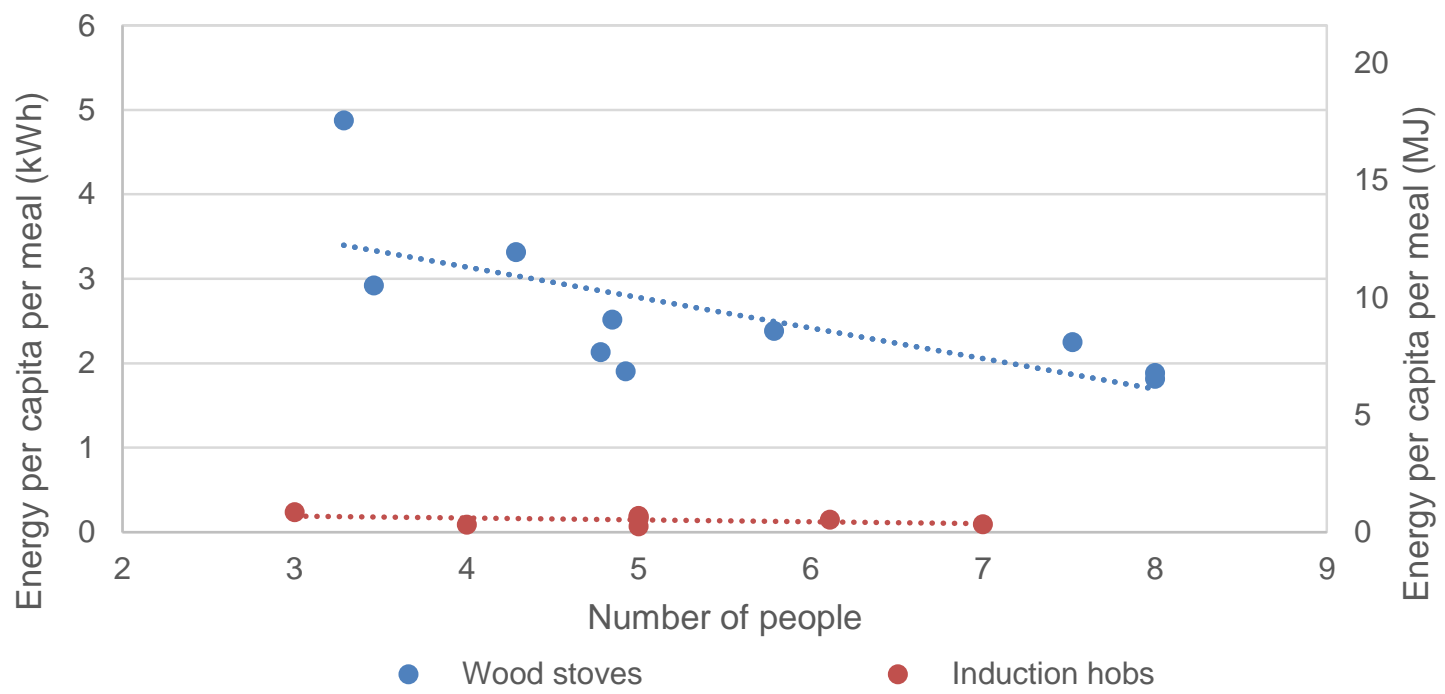

Wood stoves

- Induction hobs

444 Figure 12: Relationship between energy per capita per meal and number of people for wood and electric cooking.

445 The electrical energy data for the transition phase was analysed in further detail to 446 investigate the energy requirements of cooking different meals with the electric cookers.

447 Energy data coverage was limited, with $\mathrm{HHs} 3,8,9$ and 10 recording energy data for over $44890 \%$ of all meals cooked; $\mathrm{HHs} 4-7$ recording between $9 \%$ and $50 \%$ of energy data; and $\mathrm{HHs}$ 4491 and 2 recording no energy data at all. This was due to faults with the submeters, which 450 were low quality devices, and a lack of understanding from the participants about what data 451 to record. The average energy consumption per meal per capita for the meals with the 452 highest energy coverage is shown in Figure 13.Error! Reference source not found.

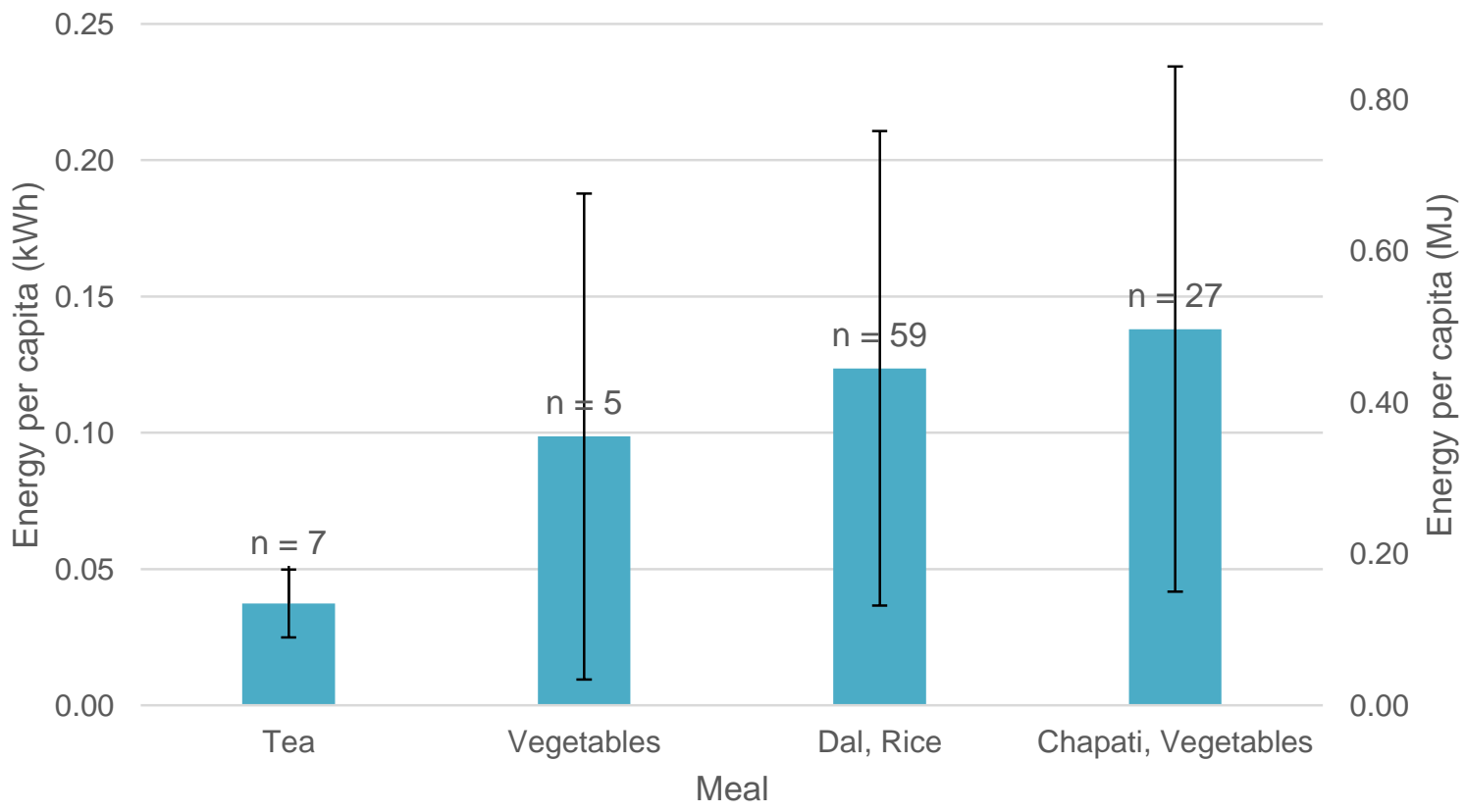

Figure 13: Average and standard deviation (error bars) of energy per capita for commonly cooked meals in the 

The electrical energy data were used to assess the affordability of electric cooking. In the study area, fuelwood can be purchased in the market at 400 NPR (\$3.37) for a $30 \mathrm{~kg}$ bundle. All the participating $\mathrm{HHs}$ collected their own fuelwood and so had no direct cost associated with it. However, assuming the market cost is the same as the labour cost for the HHs to collect wood for a day, and as approximately two full days of wood collection are required for a two-week period, the effective cost of fuelwood collection per household is $\$ 6.74$. The cost for electric cooking across the transition period for the $\mathrm{HHs}$ was $\$ 1.26-\$ 2.71$, based on the energy data of $\mathrm{HHs}$ with high data coverage, with a tariff of $120 \mathrm{NPR}(\$ 1.01)$ for the first 5 kWh consumed per month, followed by $12 \mathrm{NPR} / \mathrm{kWh}(\$ 0.10)$ after.

In order to assess affordability, participants were asked how much they would be willing to pay for electricity for cooking per month, and what an affordable price for the electric cooking system would be. All HHs reported that they would be willing to pay 300-600 NPR (\$2.52$\$ 5.04$ ) in additional monthly electricity costs. Most $\mathrm{HH}$ referred to 3,000-6,000 NPR $(\$ 25.20-\$ 50.40)$ as a reasonable price range for the electric stove and cookware, with some $\mathrm{HHs}$ who were more aware of the health benefits of a smoke-free household selecting $6,000-10,000$ NPR $(\$ 50.40-\$ 84)$.

\section{Discussion}

474 The study attempted to answer five research questions in order to assess the primary question of the feasibility of electric cooking in rural off-grid Nepali communities. Overall, it was found that electric cooking is feasible but that there are cultural, technical and economic barriers to its widespread adoption.

The study provided insight into the Nepali cooking context in terms of what is cooked, when, and how cooking is done in villages such as Simli. Generally, as well as tea, two meals were made each day: breakfast between 5 am and 9 am and dinner between 5 pm and 9 pm, as shown in Figure 6. Datasets of cooking practices were generated, revealing traditional wood cooking behaviour and how habits changed after the introduction of electric cooking.

483 Changes in behaviour while adapting to the new stoves were expected, and participants simplified their cooking, cooking a narrower range of dishes and fewer dishes per meal. The study has shown that some Nepali dishes are more compatible with electric cooking than others. Meat and fish consumption reduced, with participants noting they normally require constant stirring which they did not feel comfortable doing on the electric cookers with the provided cookware. Meat is cooked on rare occasions in rural areas, usually for festivals, which meant that participants did not have the opportunity to practice cooking meat and adapt their cooking practices to the electric stoves. All HHs reported having difficulty cooking chapati on the induction hobs, due to inexperience cooking with the hobs and their dissimilarity to wood stoves, with the hobs less able to cook the chapati evenly. Most participants cooked chapati using maize rather than wheat flour, which is thicker and therefore takes longer to cook. A study on induction stoves adoption in rural India found that only $11 \%$ of $\mathrm{HHs}$ reported cooking chapati on their induction stoves, with most preferring to use traditional stoves. Chapati cooking requires low-medium heating and an even distribution of heat across the pan. Since induction hobs cycle on and off at full or half power, and heat a ring around the centre of the pan corresponding to the location of the induction coil, they are prone to burning and unevenly cooking chapati. In the current study it 
500 is likely that the even, controllable heating provided by wood stoves, and undercooking due

501 to brownouts, caused participants to favour wood stove cooking for chapati. Therefore,

502 thicker pans with sufficient thermal mass to evenly distribute heat should be used for cooking

503 chapati on induction hobs.

504 Conversely, participants found dal and rice easy to cook in pressure cookers on the electric

505 stoves. Pressure cooker usage is commonplace in Nepal and so little adaptation was

506 required for these dishes and the time saved by not having to light a fire was clear to

507

508 participants. Regardless of unrecorded fuel stacking, dal was clearly favoured over chapati in the transition phase by six HHs, the rest of which are likely to have continued cooking

509 chapati often on their wood stoves. The high level of fuel stacking is evidence that a

510 transition to a new cooking fuel is far from straightforward, and that a total switch is

511 unrealistic, at least at first. Furthermore, the electric stoves enabled concurrent cooking with

512 wood and electricity, saving $\mathrm{HHs}$ time in their cooking processes. However, participants

513 noted that the induction hobs were beneficial due to the lack of smoke produced while

514 cooking, aligning with the aspiration of survey respondents in a previous study to have a

515 smokeless stove [38].

516 The study has provided detailed knowledge on current cooking practices and the

517 compatibility of Nepali cuisine with electric cooking, but limitations affected data quality and

518 coverage. Although exit surveys were conducted and detailed feedback collected, a

519 limitation of the study was that daily checks were not carried out to verify whether any

520 cooking had been missed. This information would have provided explanations for missed

521

522 meals and data on fuel stacking. Furthermore, as $\mathrm{HH}$ did not record data themselves, enumerators were required to be present for every cooking event, which may have led to tea

523

524 and lunch data not being recorded, and which contributed to the lack of water heating data. Future studies should include additional training on data recording and cooking Nepali dishes such as chapati and meat with electricity. A longer period of transition phase data collection would have allowed participants more time to adapt to the electric stoves and 527 therefore provided greater insight into the transition.

528 Analysis of the powerhouse electrical data showed that the total load at peak times reached full capacity on every day for which data was available, with only a maximum of ten $\mathrm{HHs}$ cooking with electricity, causing grid instability and frequent brownouts, which led to increased cooking times and food to be undercooked and wasted. Figure 14 shows a $\mathrm{HH}$ load profile on a typical day in Nepal from 2012 without electric cooking, with the transition phase cooking profile from Figure 6 superimposed. The main peaks occur at similar times, showing that Nepali people cook when demand is already high, compounding the problem of increased demand posed by electric cooking in limited capacity grids. 


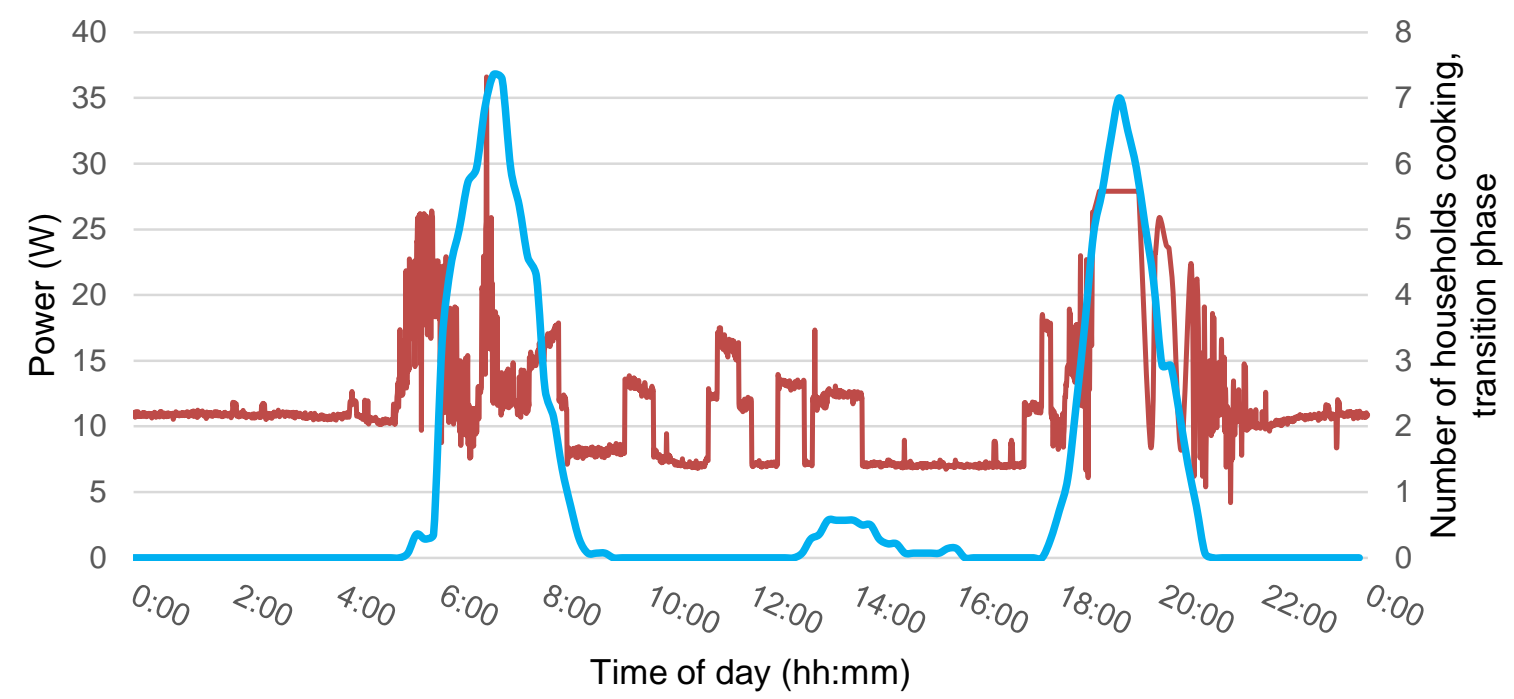

_ Typical Nepali load curve _ Transition phase cooking profile

Figure 14: Nepali household daily load profile from 2012 with the average transition phase cooking profile from this study superimposed.

Although HHs continued to cook most of their meals and dishes with the electric cookers despite the brownouts and blackouts for the following month, at the time of writing this has reduced with three HHs still using the electric cooker regularly. The main reason the other participants have reverted to their original wood stoves is the lack of reliable electrical power supply during cooking times. Thus, it has been shown that the increased load caused by electric cooking causes grid instability when most of the MHP capacity is used, which in turn reduces the feasibility of electric cooking. A limitation of the study was that powerhouse electrical data was only collected for nine days, and included missing, erroneous and repeated values. It is recommended for future studies that weeks of data are collected before and after the introduction of electric cooking using a more robust data logging system, so that the behaviour of the mini-grid can be better understood.

The study took place during monsoon season when the water flow was at its strongest. In drier months the water flow is significantly weaker and therefore the MHP generating capacity is reduced [53]. The authors' experience is that low flow during the dry season can reduce MHP generation capacity significantly, to around $75 \%$ of rated power. Therefore, electric cooking is less feasible during this time. Also, since the study, members of the community have at times diverted water from the MHP canal for irrigation, reducing the flow further and contributing to grid instability. Reduced generation capacity led to the reduction in $\mathrm{HHs}$ still using the electric cookers regularly. Cooking on wood stoves also provides space heating [40], potentially limiting the likely extent of electric cooker usage in winter. Further studies to fully understand the potential of electric cooking in the drier months should be conducted.

It is clear that, even if there is a significant amount of spare power in the mini-grid during cooking times, widespread adoption of electric cooking in communities of hundreds of households is currently impossible. Demand side management techniques, such as community agreements or GridShare, could help stabilise MHP grids with cooking loads, as discussed in literature [19] [20]. Centralised or local energy storage systems could also allow 
the cooking load to be averaged across a day rather than creating larger spikes in demand during cooking periods. Full design studies would be required for this to understand how to specify the size of storage and its effect on the mini-grid system.

This study has provided an initial understanding of the electrical energy requirements of Nepali cooking, producing data which can be used to assess solutions to the lack of spare energy for cooking in mini-grids. HH electrical energy data was collected for electric cooking for 120 meals, although for less commonly cooked meals data coverage was limited. From this data, a median electrical energy requirement of $0.25 \mathrm{kWh}$ per person per day was calculated for typical Nepali cuisine. Studies conducted under the MECS programme reported median daily electrical cooking energy consumptions per capita of $0.21 \mathrm{kWh}, 0.49$ kWh and 0.46 kWh for Zambia, Tanzania and Kenya respectively [29].

577 The daily electrical cooking energy requirement is likely to underestimate actual household 578 needs due to fuel stacking and other unrecorded heating events in the transition phase. 579 However, the meal energy consumption data is not subject to these factors. Researchers observed that typical cooking practice in the village often included preparing one dal-rice based meal, one chapati-vegetables based meal, and tea once or twice in the day. Using meal and tea energy data, a typical daily energy consumption per capita can be calculated as $0.32 \mathrm{kWh}$, which is in closer agreement with the referenced studies, as opposed to the $0.25 \mathrm{kWh}$ given by the data. For a typical median family of five a realistic daily energy consumption is therefore $1.58 \mathrm{kWh}$.

It was shown that the effective cost of wood cooking, in terms of labour time spent collecting fuelwood instead of earning, was more than the cost of electric cooking. Even when the synthetic daily energy requirement for a family of five cooking entirely with electricity is considered, the cost would be $\$ 2.73$ for the two-week period, still markedly less than the equivalent time cost of wood collection of around $\$ 6.74$. Therefore, excluding the investment cost of cooker and cookware, there is a significant cost saving that $\mathrm{HHs}$ can make by adopting electric cooking, contrary to the perceived higher cost discussed in the literature. Rural Nepalis do not necessarily attach the same monetary value to wood collection time as has been done in this analysis. However, for communities like Simli which are located close to markets with income-generation opportunities, time can be of high value.

In terms of affordability, the synthetic daily energy requirement scaled to a 30 day month of $100 \%$ electric cooking would cost $\$ 5.86$, slightly more than the higher end of the range $\mathrm{HHs}$ would be willing to pay in additional monthly electricity costs, although some inevitable fuel stacking would reduce this cost. Furthermore, the cooking systems were purchased for 12,000 NPR ( $\$ 100.80$ ) each, which is considerably more than what most HHs deemed an affordable initial cost. However, all HHs paid 4,000 NPR (\$33.60) at the end of the transition phase to keep their electric stoves and continued to use them where possible, suggesting that electric cooking is approaching affordability. Electric cooking requires an extra outlay and, therefore, in order to enable its widespread adoption, financial mechanisms to reduce initial investment costs for users will be necessary.

606 Overall, in Simli a combination of technical solutions such as energy storage cooking and financial mechanisms would be required before electric cooking can be adopted on a larger scale. This conclusion is applicable to all micro or mini grid systems with limited capacity.

610 study has identified and generated an understanding of the key factors involved in a 
611 transition to electric cooking in off-grid contexts, which can be used to assess its feasibility:

612 the available spare power and energy for cooking; the alignment of cooking windows with

613 the base load profile; variation in generation and load data over the year; planned future

614 loads; MHP behaviour under high load; cooking fuels and costs/supply; electricity tariff; and

615 MHP team competency. This understanding is transferable to any other mini-grid situation,

616 especially MHP systems.

617 SDG 7 aims to ensure access to affordable, reliable, sustainable and modern energy for all.

618 Electric cooking in MHP mini-grids can provide such energy access for cooking, although its

619 scope is currently limited to a very small number of households due to a lack of spare power

620 for cooking. This study has shown that electric cooking is approaching affordability in off-grid

621 Nepali contexts. Ensuring reliability requires consideration of the supply, maintenance and

622 repair of electric stoves, as well as MHP plant maintenance. Electric cooking can support

623 progress across nine of the other SDGs by alleviating health issues associated with biomass

624 cooking and freeing up time for work, education and leisure, especially for women, and is

625 therefore a crucial element of progress towards the SDGs [12].

\section{Conclusions}

627 This paper has reported on a study where a group of $10 \mathrm{HHs}$ in a rural Nepali village were

628 supported in the transition between wood-based stoves and electric cookers, assessing the

629 feasibility of electric cooking in rural off-grid contexts in Nepal. The cooking diaries provided

630 insight into the daily routine and cooking practices of people in rural Nepal, and generated

631 datasets of cooking habits and energy requirements of Nepali meals. The study has shown

632 that Nepali cuisine is broadly compatible with electric cooking, although participants had

633 difficulty adapting to the electric stoves for cooking chapati and meat. The mini-grid

634 powerhouse electrical data collected showed that the high power demand of electric

635 cooking, control system issues and problems with utility poles led to brownouts and

636 blackouts, which present significant barriers to electric cooking in grids with limited

637 generation capacity. The cost of electricity for cooking over the two-week period for the

638 households was $\$ 1.26$ - $\$ 2.71$, as compared to an effective cost of $\$ 6.74$ for missed labour

639 due to fuelwood collection, although the households generally have no actual cost

640 associated with wood cooking. Generally, participants considered the monthly cost of electric

641 cooking to be expensive but not beyond affordability, and were happy to pay a discounted

642 price to continue using their electric stoves. However, mini-grid instability and reduced

643 generated power during the dry season caused all but three households to revert to biomass

644 as their primary cooking fuel.

645 Overall, the study has shown that electric cooking is feasible in Simli and other rural mini-

646 grids but that currently potential uptake is limited. Even in communities with a significant

647 amount of spare power during cooking times, this conclusion applies, due to the high

648 number of households generally connected. Technical solutions to this problem such as

649 energy storage and load scheduling are required. Once technically feasible, financial

650 mechanisms to reduce initial costs for users will be necessary to enable widespread

651 adoption. However, the study has shown that, even if technically and economically feasible,

652 the transition is complicated and requires careful consideration of the cultural aspects of

653 cooking, and that fuel stacking is inevitable. Households appreciated cooking in a smoke-

654 free environment, but further awareness of the health benefits is necessary to enable a total

655 transition to electric cooking in the future. Furthermore, logistical considerations such as 
facilitating repair and maintenance of electric stoves are essential to prevent reversion to biomass.

658 The study has provided knowledge and understanding that can be applied to any mini-grid context in Nepal and other similar countries, including insight into: current cooking practices and habits; the compatibility of dishes with electric stoves; MHP mini-grid behaviour with high electric cooking demand; cooking energy requirements useful for understanding the

662 potential of energy storage to increase uptake; perceptions of initial and running costs of electric cooking; and key factors for assessing electric cooking feasibility in off-grid contexts. However, further work is required to enable widespread adoption of electric cooking in Nepal and similar communities in other countries. Further cooking diary and electrical data collection studies should be performed, in Simli or elsewhere and in different seasons, to generate more data on Nepali cooking practices, the behaviour changes required to transition to electric cooking, and hydropower grid behaviour. Data obtained during this and further studies should be used to investigate battery electric cooking and other demand side management techniques to increase the feasibility of electric cooking.

671

672

673

674

675

676

\section{Acknowledgements}

This research project has been funded through a University of Bristol QR GCRF award. QR funding is awarded to the University by Research England, based on the level of its quality related research. The field work was implemented by Kathmandu Alternative Power and Energy Group and People Energy and Environment Development Association, with support from the UNDP Nepal programme Renewable Energy for Rural Livelihoods.

\section{References}

[1] United Nations. Sustainable Development Goals Knowledge Platform: Sustainable Development Goals n.d. https://sustainabledevelopment.un.org/?menu=1300 (accessed April 17, 2019).

[2] ESMAP, GACC. The State of the Global Clean and Improved Cooking Sector. 2015.

[3] Brown E, Leary J, Davies G, Batchelor S, Scott N. eCook: What behavioural challenges await this potentially transformative concept? Sustain Energy Technol Assessments 2017;22:106-15. doi:10.1016/j.seta.2017.02.021.

[4] Smith KR, Bruce N, Balakrishnan K, Adair-Rohani H, Balmes J, Chafe Z, et al. Millions Dead: How Do We Know and What Does It Mean? Methods Used in the Comparative Risk Assessment of Household Air Pollution. Annu Rev Public Health 2014;35:185-206. doi:10.1146/annurev-publhealth-032013-182356.

[5] Killer in the kitchen - Practical Action n.d. https://practicalaction.org/ourwork/projects/killer-in-the-kitchen/ (accessed March 19, 2020).

[6] Rehfuess EA, Puzzolo E, Stanistreet D, Pope D, Bruce NG. Enablers and Barriers to Large-Scale Uptake of Improved Solid Fuel Stoves: A Systematic Review. Environ Health Perspect 2014;122:120-30. doi:10.1289/ehp.1306639.

[7] Roden CA, Bond TC, Conway S, Osorto Pinel AB, MacCarty N, Still D. Laboratory and field investigations of particulate and carbon monoxide emissions from traditional and improved cookstoves. Atmos Environ 2009;43:1170-81. doi:10.1016/j.atmosenv.2008.05.041.

[8] Patel S, Khandelwal A, Leavey A, Biswas P. A model for cost-benefit analysis of 
cooking fuel alternatives from a rural Indian household perspective. Renew Sustain Energy Rev 2016;56:291-302. doi:10.1016/j.rser.2015.11.047.

[9] Joshi SB, Jani AR. Design, development and testing of a small scale hybrid solar cooker. Sol Energy 2015;122:148-55. doi:10.1016/j.solener.2015.08.025.

[10] Watkins T, Arroyo P, Perry R, Wang R, Arriaga O, Fleming M, et al. Insulated Solar Electric Cooking - Tomorrow's healthy affordable stoves? Dev Eng 2017;2:47-52. doi:10.1016/j.deveng.2017.01.001.

[11] Gius G, Walker M, Li A, Adams NJ, Van Buskirk R, Schwartz P. Hot diodes!: Dirt cheap cooking and electricity for the global poor? Dev Eng 2019;4. doi:10.1016/j.deveng.2019.100044.

[12] Batchelor S, Brown E, Scott N, Leary J. Two Birds, One Stone-Reframing Cooking Energy Policies in Africa and Asia. Energies 2019;12:1591. doi:10.3390/en12091591.

[13] Leary J, Scott N, Serenje N, Mwila F, Associate SB, Leach M, et al. Opportunities \& Challenges for eCook Zambia. 2019.

[14] Batchelor S, Scott N, Leary J. eCook - the near future landscape of cooking in urban areas in Africa 2017.

[15] Banerjee M, Prasad R, Rehman IH, Gill B. Induction stoves as an option for clean cooking in rural India. Energy Policy 2016;88:159-67. doi:10.1016/j.enpol.2015.10.021.

[16] Couture TD, Jacobs DD. Beyond Fire: How to achieve electric cooking. 2019.

[17] Lombardi F, Riva F, Sacchi M, Colombo E. Enabling combined access to electricity and clean cooking with PV-microgrids: new evidences from a high-resolution model of cooking loads. Energy Sustain Dev 2019;49:78-88. doi:10.1016/j.esd.2019.01.005.

[18] Leary J, Batchelor S, Leach M, Brown E, Alsop A. eCook Global Market Assessment Where will the transition take place first? 2018. doi:10.13140/RG.2.2.22612.30082.

[19] Quetchenbach TG, Harper MJ, Robinson IV J, Hervin KK, Chase NA, Dorji C, et al. The GridShare solution: a smart grid approach to improve service provision on a renewable energy mini-grid in Bhutan. Environ Res Lett 2013;8:014018. doi:10.1088/1748-9326/8/1/014018.

[20] Leary J, Hlaing W, Myint A, Win P, Phyu M, Moe ET, et al. Opportunities \& Challenges for eCook Myanmar. 2019.

[21] Solar Electric Cooking | eCook, about cooking with photovoltaics, and enhancing micro and national grids with a battery cooker combination. n.d. https://elstove.com/ (accessed April 17, 2019).

[22] Modern Energy Cooking Services - Cooking to World Health Standards n.d. https://www.mecs.org.uk/ (accessed March 30, 2020).

[23] Batchelor S, Brown E, Leary J, Scott N, Alsop A, Leach M. Solar electric cooking in Africa: Where will the transition happen first? Energy Res Soc Sci 2018;40:257-72. doi:10.1016/j.erss.2018.01.019.

[24] Batchelor S. Is it time for Solar Electric Cooking in Africa? Gamos Concept Note. 2013.

[25] Leach M, Oduro R. Preliminary design and analysis of a proposed solar and battery electric cooking concept: costs and pricing. 2015. doi:10.12774/eod_cr.november2015.leachm. 
[26] Slade R. Key assumptions and concepts on potential for solar electric cooking: Batteries capable of operating suitably in 'harsh' conditions in the developing world. 2015. doi:10.12774/eod_cr.november2015.slader.

[27] Brown E, Sumanik-Leary J. A review of the behavioural change challenges facing a proposed solar and battery electric cooking concept. 2015. doi:10.12774/eod_cr.browneetal.

[28] Batchelor S, Leary J, Sago S, Minja A, Chepkurui K, Sawe E, et al. Opportunities \& Challenges for eCook Tanzania. 2019.

[29] Batchelor S, Brown E, Scott N, Leary J. Experiences of Electric Pressure Cookers in East Africa? 2019.

[30] Asian Development Bank. Gender Equality and Social Inclusion Assessment of the Energy Sector: Manila, Philippines: 2018. doi:10.22617/TCS179164-2.

[31] Nepal Electricity Authority (NEA). Annual report of Nepal Electricity Authotity, 2018/19 2019;2018/19:1-230.

[32] Nepal Ministry of Finance. Economic Survey 2017/18. 2018.

[33] Nepal Central Bureau of Statistics. Annual Household Survey 2014/15. 2016.

[34] Pradhan BB, Limmeechokchai B. Electric and Biogas Stoves as Options for Cooking in Nepal and Thailand. Energy Procedia 2017;138:470-5. doi:10.1016/j.egypro.2017.10.227.

[35] Bhandari R, Pandit S. Electricity as a Cooking Means in Nepal_A Modelling Tool Approach. Sustainability 2018;10:2841. doi:10.3390/su10082841.

[36] Government of Nepal, Ministry of Energy Water Resources and Irrigation. Current Status and the Roadmap for the Future. Kathmandu, Nepal: 2018.

[37] Pokharel S. Energy economics of cooking in households in Nepal. Energy 2004;29:547-59. doi:10.1016/j.energy.2003.10.015.

[38] Sanchez T, Dennis R, Pullen KR. Cooking and lighting habits in rural Nepal and Uganda n.d. doi:10.1177/0957650913498872.

[39] Asian Development Bank. Sustainable Energy Access Planning: A Case Study. Manila, Philippines: 2018. doi:10.22617/TCS189194.

[40] Pokharel TR, Rijal HB, Shukuya M. A field investigation on indoor thermal environment and its associated energy use in three climatic regions in Nepal. Energy Build 2020:110073. doi:10.1016/j.enbuild.2020.110073.

[41] Kar A, Zerriffi $\mathrm{H}$. From cookstove acquisition to cooking transition: Framing the behavioural aspects of cookstove interventions. Energy Res Soc Sci 2018;42:23-33. doi:10.1016/j.erss.2018.02.015.

[42] Leary J, Batchelor S. Cooking Diaries Protocols. 2018. doi:10.13140/RG.2.2.15851.18728.

[43] eCook. Forward looking guidance | Solar Electric Cooking n.d. https://elstove.com/forward-looking-guidance/ (accessed August 8, 2019).

[44] Batchelor S, Leary J, Sago S, Minja A, Sawe E, Shuma J, et al. eCook Tanzania Country Report Opportunities and Challenges in Tanzania. 2018. doi:10.13140/RG.2.2.31912.01289.

[45] Environmental Protection Agency, Partnership for Clean Indoor Air (PCIA), Clean 
Cooking Alliance. The Water Boiling Test. 2014.

[46] Bailis R. Controlled Cooking Test (CCT). 2004.

[47] Bailis R. Kitchen Performance Test (KPT). 2007.

[48] Chan J, Lubitz W. Electronic load controller (ELC) design and simulation for remote rural communities: A powerhouse ELC compatible with household distributed-ELCs in Nepal. GHTC 2016 - IEEE Glob Humanit Technol Conf Technol Benefit Humanit Conf Proc 2016:360-7. doi:10.1109/GHTC.2016.7857306.

[49] Campbell Scientific. Campbell Scientific CR1000 data logger datasheet 2017. https://s.campbellsci.com/documents/us/product-brochures/s_cr1000.pdf (accessed April 18, 2019).

796

797

[50] Nepal Central Bureau of Statistics. National Population and Housing Census 2011. 2014.

798

799

[51] IMU/RCO. Nepal: Rukum District Map with Constituency Boundary 2010. http://un.org.np/sites/default/files/Rukum_0.pdf (accessed August 27, 2019).

800

801

802

803

804

[52] Sepp S. Multiple-Household Fuel Use - a balanced choice between firewood, charcoal and LPG. 2014.

[53] Chalise SR, Kansakar SR, Rees G, Croker K, Zaidman M. Management of water resources and low flow estimation for the Himalayan basins of Nepal. J Hydrol 2003;282:25-35. doi:10.1016/S0022-1694(03)00250-6.

805

806

807

808 The survey was translated into English from Nepali.

Table 3: Exit survey used after transition phase to understand participants' experiences of the electric stoves

\begin{tabular}{|c|c|c|c|c|c|}
\hline \multirow{2}{*}{\multicolumn{2}{|c|}{$\begin{array}{l}\text { Name: } \\
\text { Electricity user ID: }\end{array}$}} & \multicolumn{4}{|c|}{ User Feedback Form } \\
\hline & & \multicolumn{4}{|l|}{ Date: } \\
\hline & Questions & \multicolumn{4}{|c|}{ Rate from 1 to 5} \\
\hline \multirow[t]{2}{*}{1} & $\begin{array}{l}\text { How much would you rate the electrical } \\
\text { cooker in terms of user } \\
\text { friendliness? }\end{array}$ & 1 & 2 & 34 & 5 \\
\hline & Comments: & very hard & & & very easy \\
\hline \multirow[t]{2}{*}{2} & $\begin{array}{l}\text { How much would you rate the } \\
\text { cooking time performance of the } \\
\text { electrical cooker? }\end{array}$ & 1 & 2 & 34 & 5 \\
\hline & Comments: & To slow & & & To fast \\
\hline \multirow[t]{2}{*}{3} & $\begin{array}{l}\text { How safe did you find the electrical } \\
\text { cooker? }\end{array}$ & 1 & 2 & 34 & 5 \\
\hline & Comments: & $\begin{array}{l}\text { Not safe at } \\
\text { all }\end{array}$ & & & Too safe \\
\hline
\end{tabular}




\begin{tabular}{|c|c|c|c|c|c|}
\hline \multirow[t]{2}{*}{4} & $\begin{array}{l}\text { How much would you rate that the } \\
\text { electrical cooker saves time than } \\
\text { wood stoves? }\end{array}$ & 1 & 2 & 34 & 5 \\
\hline & Comments: & no time & & & $\begin{array}{l}\text { Saves } \\
\text { time }\end{array}$ \\
\hline \multirow[t]{2}{*}{5} & $\begin{array}{l}\text { How would you rate on the starting cost } \\
\text { of the electrical cookers (12000 range } \\
\text { including the utensils)? }\end{array}$ & 1 & 2 & 34 & 5 \\
\hline & Comments: & $\begin{array}{l}\text { Too } \\
\text { expensive }\end{array}$ & & & $\begin{array}{l}\text { Price is } \\
\text { fine }\end{array}$ \\
\hline \multirow[t]{2}{*}{6} & $\begin{array}{l}\text { How would you rate on the monthly } \\
\text { running cost of the electrical } \\
\text { cookers? }\end{array}$ & 1 & 2 & 34 & 5 \\
\hline & Comments: & $\begin{array}{l}\text { Too } \\
\text { expensive }\end{array}$ & & & $\begin{array}{l}\text { Price is } \\
\text { fine }\end{array}$ \\
\hline \multirow[t]{2}{*}{7} & $\begin{array}{l}\text { How much would you rate on the } \\
\text { electricity service provided by the } \\
\text { utility? }\end{array}$ & 1 & 2 & 34 & 5 \\
\hline & Comments: & Worst & & & Great \\
\hline 8 & $\begin{array}{l}\text { Would you still use wood stove even } \\
\text { though the electric cooker is more } \\
\text { convenient? }\end{array}$ & YES & & & NO \\
\hline \multirow[t]{2}{*}{9} & $\begin{array}{l}\text { How much would you rate on the value } \\
\text { of smoke free environment? }\end{array}$ & 1 & 2 & 34 & 5 \\
\hline & Comments: & $\begin{array}{l}\text { No value at } \\
\text { all }\end{array}$ & & & $\begin{array}{l}\text { Extremely } \\
\text { valuable }\end{array}$ \\
\hline \multirow[t]{5}{*}{10} & $\begin{array}{l}\text { What would be the most comfortable } \\
\text { price range considering the value of } \\
\text { electric cookers? }\end{array}$ & \multicolumn{4}{|c|}{$\begin{array}{l}\text { How much cost of electricity would you be } \\
\text { willing to pay for using electric stoves per } \\
\text { month? }\end{array}$} \\
\hline & NPR - 1000 to 3000 & \multicolumn{4}{|l|}{ NPR $300-600$} \\
\hline & NPR - 3000 to 6000 & \multicolumn{4}{|l|}{ NPR $600-900$} \\
\hline & NPR - 6000 to 10,000 & \multicolumn{4}{|l|}{ NPR $900-1200$} \\
\hline & NPR $-10,000$ to 15,000 & \multicolumn{4}{|l|}{ NPR 1200-1500 } \\
\hline 11 & $\begin{array}{l}\text { Were you using the wood stove side by } \\
\text { side with the electric cookers? If yes } \\
\text { what are those items? }\end{array}$ & & & & \\
\hline 12 & $\begin{array}{l}\text { During } 14 \text { days of survey how many } \\
\text { times did the electricity went out and } \\
\text { what did you do at that time? }\end{array}$ & & & & \\
\hline 13 & Other feedback: & & & & \\
\hline
\end{tabular}

